$$
\begin{gathered}
\text { Nevista Brasileira de Geomorfologia } \\
\text { Www.ugb.org.br } \\
\text { ISSN 2236-5664 }
\end{gathered}
$$

\title{
APLICAÇÃO DE DADOS ERS, ENVISAT E SENTINEL PARA DETECÇÃO DE MUDANÇAS NOS AMBIENTES COSTEIROS AMAZÔNICOS
}

\section{ERS, ENVISAT AND SENTINEL DATA APPLICATION FOR CHANGE DETECTION IN AMAZON COASTAL ENVIRONMENTS}

\author{
Ulisses Silva Guimarães \\ Centro Gestor e Operacional do Sistema de Proteção da Amazônia \\ SPO, Área 5, Quadra 3, Bloco K, Brasília, Distrito Federal. CEP 70610-200. Brasil \\ Email: ulisses.silva@sipam.gov.br
}

Igor da Silva Narvaes

Centro Regional da Amazônia, Instituto Nacional de Pesquisas Espaciais Parque de Ciência e Tecnologia do Guamá, 2651, Belém, Pará. CEP 66077-830. Brasil

Email: igor.narvaes@inpe.br

Maria de Lourdes Bueno Trindade Galo

Faculdade de Ciências e Tecnologia, Universidade Estadual Paulista

Rua Roberto Simonsen, 305, Presidente Prudente, São Paulo. CEP 19060-900. Brasil

Email:mlourdes@fct.unesp.br

\section{Informações sobre o Artigo}

Recebido (Received):

03/02/2016

Aceito (Accepted):

$11 / 02 / 2017$

\section{Palavras-chave:}

Radar de Abertura Sintética, Processamento $S A R$ em amplitude, Mapeamento Morfológico Costeiro e Detecção de Mudanças Costeiras.

Keywords:

Synthetic Aperture Radar, Amplitude SAR Processing Chain, Coastal Morphological Mapping and Coastal Change Detection.

\begin{abstract}
Resumo:
Ambientes costeiros são naturalmente vulneráveis a processos morfodinâmicos como erosão e deposição de sedimentos e essa condição se intensifica em condições tropicais úmidas. A costa amazônica é marcada pela elevada descarga de sedimentos e água doce sob influência do rio Amazonas e caracterizada por uma ampla plataforma continental, extensas planícies inundáveis e planaltos mais elevados formados em rochas sedimentares mais antigas. O presente estudo apresenta uma abordagem para mapeamentos morfológicos e detecção de mudanças em zonas costeiras, baseado em dados de radar de abertura sintética (Synthetic Aperture Radar-SAR) em banda C, em áreas com intensa dinâmica costeira e de constante cobertura de nuvens. O método se baseia na cadeia de processamento $S A R$ em amplitude aplicada a um perfil temporal de dados ERS1/2, ENVISAT e SENTINEL-1A entre 1992 a 2015 e fornecidos pela European Space Agency (ESA). Os ambientes costeiros foram discriminados pela informação primária do coeficiente de retroespalhamento, e dados auxiliares derivados da textura de Haralick e índice de forma. As mudanças costeiras detectadas no período se estenderam por uma área de $646,15 \mathrm{~km}^{2}$, com balanço sedimentar erosivo em $-2,32 \mathrm{~km}^{2}$ e sob a taxa de $-0,10 \mathrm{~km}^{2}$. ano ${ }^{-1}$. O perfil temporal de mudanças costeiras está em equilíbrio e apresentou condição erosiva no período de 1992 a 1993 e 1996 a 1999 e, enquanto que no período de 1993 a 2006 e 2006 a 2015 ocorreu uma condição de acresção. A acurácia do mapeamento dos ambientes e das mudanças
\end{abstract}


costeiras resultaram, respectivamente, em exatidão global de 78,35\% e 48,54\%, e coeficiente Kappa de 0,65 e 0,32. Os dados ERS, ENVISAT e SENTINEL permitiram mapear satisfatoriamente as mudanças morfológicas no relevo plano e dinâmico da costa amazônica, devido à disponibilidade de uma série histórica de imagens SAR em banda C, com polarização vertical paralela e incidência de íngreme a rasante. Tal aplicação foi essencial ao monitoramento sistemático de linha de costa em escala espacial regional (1:250.000) e escala temporal eventual (anual a decadal).

\begin{abstract}
:
The Amazon coast is marked by a high discharge of sediment and fresh water under the influence of the Amazon river. A broad continental shelf, extensive flood flats and higher plateaus, formed in older sedimentary rocks, characterize this coast. Coastal environments are naturally vulnerable to morphodynamic processes, such as erosion and sediment deposition, and this condition intensifies in wet tropical conditions. This study presents an approach for morphological mapping and change detection in coastal zone, based on C-band Synthetic Aperture Radar (SAR), in areas with intense coastal dynamics and systematic cloud cover. The method is based on the amplitude SAR processing chain for a temporal profile of ERS-1/2, ENVISAT and SENTINEL-1A data, acquired between 1992 and 2015 and provided by the European Space Agency (ESA). The backscattering coefficient primary information, as well as auxiliary data extracted from the Haralick texture and shape indices were used to describe coastal environments. The total area of coastal changes detected between 1992 and 2015 was $646.15 \mathrm{~km}^{2}$. year ${ }^{-1}$, with erosive sedimentary balance in $-2.32 \mathrm{~km}^{2}$ under the rate of $-0,10 \mathrm{~km}^{2}$.year-1. The time profile of coastal changes is in equilibrium and presented an erosive condition in the period from 1992 to 1993 and from 1996 to 1999, while in the period from 1993 to 2006 and 2006 to 2015 the accretion condition occurred. The accuracy of the maps of environments and coastal changes, respectively obtained an overall accuracy of $78.35 \%$ and $48.54 \%$, and Kappa coefficient of 0.65 and 0.32 . The ERS, ENVISAT and SENTINEL data allowed a satisfactory mapping of the morphological changes in the flat and dynamic relief of the Amazonian coast due to the availability of a historical series of C-band SAR images with parallel vertical polarization and steeper to shallow incidence. Such application was essential for the systematic monitoring of the shoreline on a regional spatial scale $(1: 250,000)$ and eventual temporal scale (annual to decadal).
\end{abstract}

\section{Introdução}

A zona costeira corresponde à extensão entre terra e mar, com recorrência de processos costeiros dominados por rios, marés, ventos, correntes e ondas, durante os últimos 1,8 milhões de anos até o presente. Nela estão incluídos ambientes marinhos deposicionais e erosionais, em continente adentro até o contato com o substrato consolidado e em direção ao mar até a quebra da plataforma continental (DALRYMPLE et al., 1992; MASSELINK et al., 2003; MUEHE, 1994). Ambientes costeiros são susceptíveis às mudanças morfológicas, as quais aliadas a mudanças climáticas e atividades humanas constituem risco e provocam eventos danosos como inundações, ondas elevadas, tempestades severas, tsunamis, ciclones, erosão costeira, derivas continentais e redistribuição sedimentar (NICHOLLS et al., 2007; NICHOLLS; CAZENAVE, 2010).

Eventos danosos têm se intensificado na zona costeira mundial, normalmente vinculados à agentes físicos em diversas escalas espaço-temporais, influenciando na subida do nível do mar na ordem de $3,4 \mathrm{~mm} \cdot \mathrm{ano}^{-1}$ (NEREM et al., 2010), prevendo-se que alcance até 0,74 m em 2100 (IPCC, 2014b); à flutuações de clima rápidas e severas, associadas ao aquecimento global, com projeção de elevação de temperaturas de até $4^{\circ} \mathrm{C}$ para 2100 (IPCC, 2014a); distúrbios por impactos ambientais que atingem $40 \%$ dos grandes ecossistemas marinhos (UNDP, 2012); e ao modelo de desenvolvimento e ocupação humana, que adensa $38 \%$ da população mundial na faixa litorânea em até $100 \mathrm{~km}$, sendo que $3,6 \%$ vive em áreas baixas a até 5 metros da atual linha de costa (UNITED NATIONS, 2016). Em termos de recursos marinhos e costeiros, a zona costeira contribui com $63 \%$ do produto nacional bruto mundial (UNDP, 2012).

A costa brasileira apresenta alta diversidade de ambientes, estende-se por $8.698 \mathrm{~km}$ e está compartimentada em cinco complexos litorâneos com subdivisão em dezenove macrocompartimentos (MUEHE, 2006a; SILVEIRA, 1964; ZAMBONI; NICOLODI, 2008). Sua herança geológica advém essencialmente da 
gênese do oceano Atlântico e recentemente aos ciclos transgressivos-regressivos no Quaternário. O clima varia de tropical a temperado com forte influência da Zona de Convergência Intertropical (ZCIT), Anticiclone Tropical do Atlântico Sul (ATAS) e Anticiclones Polares Migratórios (APM), ocorrendo desde micromarés a macromarés e as correntes dominantes são a Norte Brasileira, Sul Equatorial e do Brasil (MUEHE, 2006a; TESSLER; GOYA, 2005). A zona costeira brasileira concentra cerca de $26,6 \%$ da população, com um déficit de saneamento básico da ordem de $80 \%$ (ASMUS et al., 2006; IBGE, 2010).

A Zona Costeira Amazônica (ZCA) encontra-se na faixa norte tropical da costa brasileira e tem o rio Amazonas como o principal contribuinte de água doce e sedimento, o que o torna um ambiente costeiro único, constituído por um complexo deltaico-estuarino, devido ao equilíbrio entre um vale afogado durante o Quaternário, aliado a enorme descarga de sedimentos (MEADE et al., 1985; NITTROUER et al., 1986). A costa amazônica é descrita como tropical úmida, com alta precipitação, macromarés semidiurnas, ampla plataforma continental, propiciando a formação de planícies extensas inundadas periodicamente e planaltos rebaixados suportados por rochas sedimentares antigas (COSTA et al., 1991; ELROBRINI et al., 2006; GEYER et al., 1996; MEADE et al., 1985). A ZCA se estende ao longo da linha de costa sob influência da pluma de sedimentos do rio Amazonas, especificamente no Brasil, compondo cerca de 1.200 $\mathrm{km}$ de litoral em linha reta. Estima-se que abrigue uma população de 5,71 milhões, o que corresponde a 2,67\% da população brasileira vivendo em áreas de até $50 \mathrm{~m}$ de altitude e taxas de progradação costeira em torno de 59,9 $\mathrm{km}^{2}$. ano ${ }^{-1}$ (IBGE, 2010; NASCIMENTO et al., 2013; ZAMBONI; NICOLODI, 2008). Essas condições tornam a ZCA singular, o que demanda intervenções e a necessidade prévia de discriminar e monitorar mudanças morfológicas em escala espacial local $(\leq 10 \mathrm{~m})$ e escala temporal eventual (anos).

A demanda pelo mapeamento e monitoramento dos ambientes costeiros tropicais úmidos pressupõe a aquisição de dados no espectro de microondas em detrimento de dados ópticos, devido não apenas à maior sensibilidade dos sistemas de microondas às características morfométricas da paisagem, mas também pela possibilidade de adquirir imagens em condições adversas de nebulosidade, inerentes às faixas litorâneas (NAPIERALSKI et al., 2013; WANG, 2010). Os sistemas sensores de radar de abertura sintética (Synthetic Aperture Radar-SAR) são sistemas coerentes, os quais realizam medições em direção e alcance com previsibilidade e melhora na resolução espacial, em função da síntese de uma antena virtual, baseada em princípios de interferência e na cadência de feixes sob efeito Doppler (WOODHOUSE, 2006). As características do sinal de retorno captado pelos sistemas SAR dependem não só da interação do comprimento de onda utilizado com as propriedades eletrogeométricas dos alvos, mas também do ângulo de incidência e o grau de umidade do objeto, sendo sensível a variação topográfica em macro e micro-escala. Além disso, possui capacidade de operação diurna e noturna, menor susceptibilidade ao efeito da atmosfera, geometria de aquisição controlada, alta amostragem espacial e revisita (HENDERSON; LEWIS, 1998).

O mapeamento da ZCA tem sido abordado por sensores ópticos e SAR, com destaque aos estudos das unidades de paisagem com suscetibilidade natural a erosão e derramamento de óleo (DE ANDRADE et al., 2010; FILHO et al., 2009; GUIMARÃES, 2011b; RODRIGUES; SOUZA-FILHO, 2012); caracterização sedimentológica, espectral, textural e parâmetros biofísicos de alvos (COUGO et al., 2015; FRANÇA et al., 2007; GUIMARÃES, 2011a; SANTOS, 2006; TEIXEIRA, 2011); reconhecimento de ambientes úmidos costeiros e mensuração espacial de sistemas erosivos/deposicionais (BATISTA et al., 2007; FRANÇA; SOUZA-FILHO, 2003; NASCIMENTO et al., 2013; SANTOS, 2006; SOUZA-FILHO et al., 2011; SOUZA FILHO et al., 2006). Esses estudos permitiram inferir grandes extensões contínuas de manguezais, balanço sedimentar de acrescional a equilibrado e discriminação de ambientes, devido à boa performance por imagens ópticas multiespectrais, banda L polarizada e textura.

Iniciativas como a da European Space Agency (ESA) têm permitido a aquisição e disponibilização de dados SAR acurados para observação terrestre, a partir dos programas Global Monitoring Environment and Security (GMES) e seu sucessor Copernicus. No caso específico de sensores de microondas, os dados $S A R$ da ESA representam a maior série temporal no intervalo espectral da banda $\mathrm{C}$ com cobertura global, e destaca-se o potencial para aprimorar a detecção de mudanças morfológicas costeiras, devido à série de satélites de observação terrestres que é composta pelas plataformas European Remote Sensing (ERS), Environmental Satellite (ENVISAT) e SENTINEL (ASCHBACHER; MILAGRO-PÉREZ, 
2012). As duas primeiras plataformas foram configuradas em órbitas similares, em um arranjo denominado tandem, que juntas viabilizaram a descorrelação temporal entre 1 dia à 28 minutos, e aumentaram a possibilidade do emprego de técnicas interferométricas (FERRETTI et al., 2007; WEGMÜLLER et al., 2009). Já a última plataforma é uma continuidade da série e têm como característica a operação com duas estações idênticas, aprimorando a capacidade de revisita para 6 dias (ESA, 2015a).

Diante da disponibilidade de dados históricos $S A R$ em banda $\mathrm{C}$, dos novos sistemas colocados em operação e face à necessidade de discriminar ambientes e monitorar mudanças, este estudo propõe uma abordagem metodológica, baseada na cadeia de processamento $S A R$ em amplitude, aplicada ao mapeamento morfológico dos ambientes costeiros amazônicos. Nesse sentido, esses ambientes foram descritos, mapeados, as mudanças ocorridas no período foram detectadas e avaliadas, e por fim, realizou-se uma análise da qualidade temática do resultado obtido, em condição de elevada dinâmica, chuvas e nebulosidade severas, características do complexo deltaico-estuarino do rio Amazonas.

\section{2. Área de Estudo}

A foz do rio Amazonas propicia a formação de um sistema costeiro singular, classificado como deltaico-estuarino (NITTROUER et al., 1986). Essa desembocadura alcança vazões na ordem de 6,3 trilhões de $\mathrm{m}^{3}$.ano ${ }^{-1}$ e corresponde ao segundo maior aporte sedimentar do mundo com 1,2 bilhões de ton.ano ${ }^{-1}$, acrescentando-se as contribuições dos demais rios do Amapá, Pará e Maranhão, tem-se 30 ton. ano ${ }^{-1} \cdot \mathrm{km}^{-2} \mathrm{de}$ aporte sedimentar à planície costeira e à plataforma continental (GEYER et al., 1996; KJERFVE et al., 2002; MEADE et al., 1985; PEREIRA et al., 2012; SOUZA-FILHO et al., 2005). Em adição, consta que a plataforma continental interna na costa do Amapá está sob forte sedimentação com taxa de $10 \mathrm{~cm} \cdot$ ano $^{-1}$ (NITTROUER et al., 1995).

Essas condições extremamente dinâmicas foram consideradas na especificação da área de estudos que, face à característica de mapeamento temporal, foi delineada pela interseção das faixas de imageamento definidas pelas órbitas dos satélites ERS-1/2, ENVISAT e SENTINEL-1A, que cobrem a foz do rio Amazonas entre a costa do Amapá e a Ilha de Marajó (Figura 1).

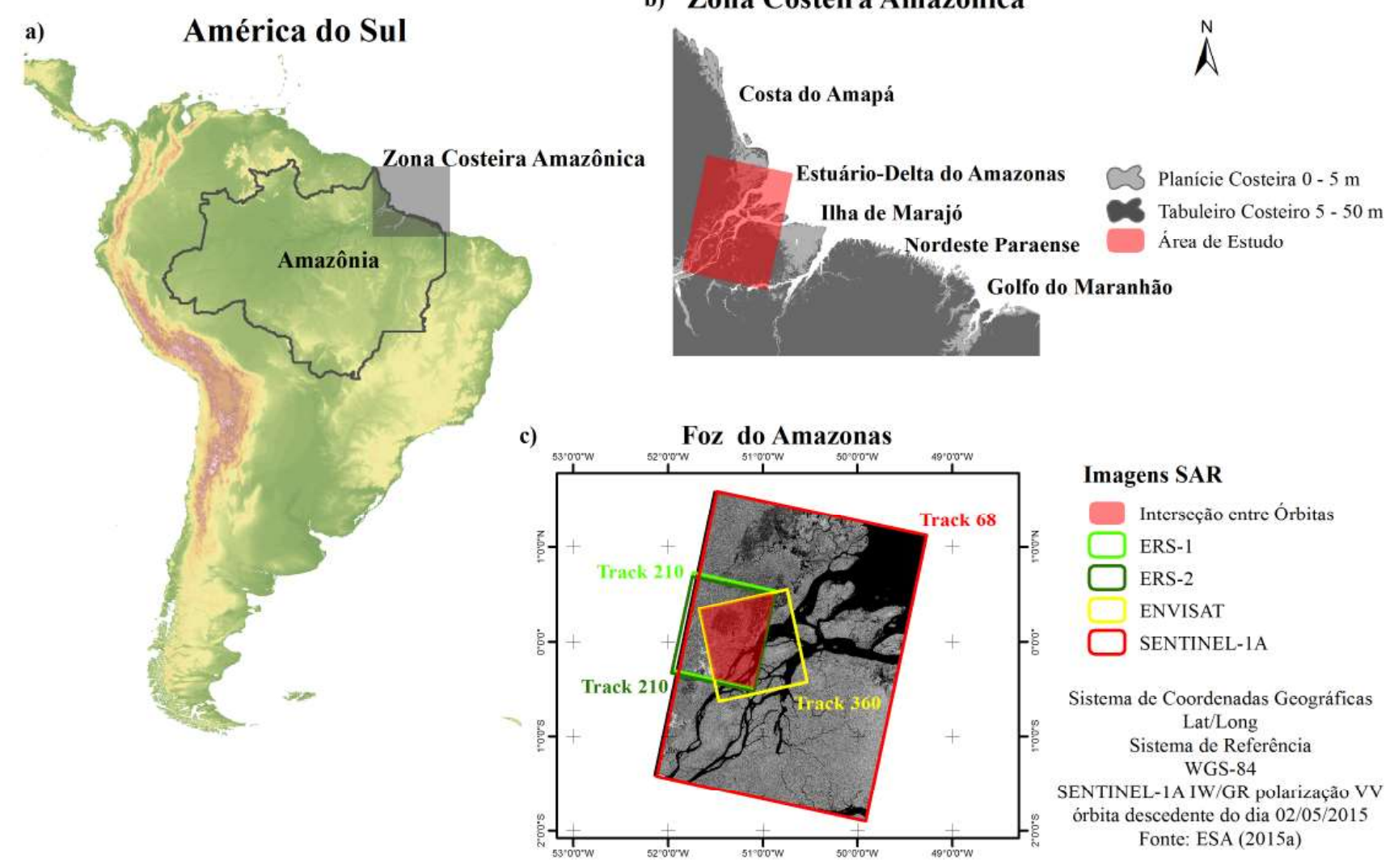

b) Zona Costeira Amazônica

Figura 1 - a) Localização da zona costeira amazônica no território brasileiro; b) compartimentos da costa amazônica e esboço das unidades de relevo planicie e planalto costeiro; c) localização das cenas $\boldsymbol{S A R}$ utilizadas no estudo. 
As condições hidrodinâmicas da costa amazônica são resposta do fluxo e refluxo de macromarés semidiurnas com amplitudes entre 5 a $3 \mathrm{~m}$, correntes que durante a preamar alcançam 2,1 a 1,9 nós e ondas de altura entre 0,3 e 1,5 m (EL-ROBRINI et al., 2006).

O clima é tropical quente-úmido com forte influência da Zona de Convergência Intertropical (ZCIT), o que propicia um período mais chuvoso de dezembro a maio com médias de $3000 \mathrm{~mm}$ e ventos médios de $6,2 \mathrm{~m} \cdot \mathrm{s}^{-1} \mathrm{e}$ um período menos chuvoso de junho a novembro, com médias de $350 \mathrm{~mm}$ e ventos médios de $7 \mathrm{~m} . \mathrm{s}^{-1}$ (MARTORANO, 1993).

$\mathrm{Na}$ costa amazônica se sobressaem duas composições vegetacionais: i) formações florestais, relacionadas a tipologia ombrófila (densa e aberta), secundárias resultantes de rebrota, aluviais e manguezais; e, ii) formações campestres ou não-florestais, representadas por formações pioneiras, campos, savanas/cerrados e restingas (FRANÇA, 2003; PROJETO RADAM BRASIL, 1974; SANTOS, 2006).

O contexto geológico/geomorfológico local é caracterizado por duas unidades básicas de relevo. A primeira denominada planalto costeiro, refere-se a um relevo de degradação sustentado, em maior parte, por sedimentos consolidados da formação Barreiras e grupo Pós-Barreiras, estes constituídos por arenitos e argilitos, geralmente ocorrendo em cotas altimétricas acima de $5 \mathrm{~m}$. A segunda unidade é a planície costeira, classificada como relevo de agradação e caracterizada por camadas argilosas à arenosas de origem fluviomarinha, formam terraços, cordões, deltas de marés e planícies lamosas ao longo da costa em cotas altimétricas, em grande parte abaixo de $5 \mathrm{~m}$ (COSTA et al., 1991; EL-ROBRINI et al., 2006).

\section{Materiais e Métodos}

\subsection{Dados SAR}

Dados SAR aplicados a estudos geomorfológicos devem considerar prioritariamente o azimute de visada (cerca de $80^{\circ}$ ou $\left.280^{\circ}\right)$ e o ângulo de incidência $\left(20^{\circ}\right.$ $\leq \theta \leq 60^{\circ}$ ) sob o relevo, essas características proporcionam contraste do sinal em vertentes orientadas sob determinada direção e controlam o efeito de sombras e distorções geométricas como encurtamento de rampa e inversão de relevo (HENDERSON; LEWIS, 1998; WOODHOUSE, 2006).

De acordo com as características de geometria de aquisição elucidadas acima, os dados ERS, ENVISAT e SENTINEL foram obtidos em polarização vertical na emissão e vertical na recepção (VV), o que significa que o vetor senoide do campo elétrico tem posição perpendicular em relação a superfície terrestre. Os dados foram tomados com visada a direita em relação ao trajeto da plataforma, com azimute em órbita ascendente de $\pm 80^{\circ}$ (ENE) e descendente de $\pm 280^{\circ}$ (WNW).

As fontes de dados primárias incluem imagens SAR dos sistemas sensor ERS-1/2 e ENVISAT, disponíveis em modo Image Mode (IM) e nível Single Look Complex (SLC), obtidos por meio de submissão de proposta científica para (C) ESA (2014). Em adição obteve-se imagens SAR do sistema sensor SENTINEL-1A, disponíveis em modo Interferometric Wide Swath (IW) e nível Ground Range (GR) (ESA, 2015b). As especificações desses sistemas estão na Tabela 1.

Tabela 1: Caraterísticas das cenas SAR utilizadas e variáveis físicas na data de aquisição das imagens. *Fonte: (C) ESA (2014); (ESA, 2015b)

\begin{tabular}{|c|c|c|c|c|c|c|}
\hline Parâmetros & \multicolumn{2}{|c|}{ ERS-1* } & \multicolumn{2}{|c|}{ ERS-2* } & ENVISAT* & SENTINEL-1A \\
\hline Modo/Produto & \multicolumn{5}{|c|}{ IM/SLC } & IW/GR \\
\hline Faixa Imageada & \multicolumn{4}{|c|}{$100 \mathrm{~km}$} & $105 \mathrm{~km}$ & $250 \mathrm{~km}$ \\
\hline Sensor & \multicolumn{4}{|c|}{ AMI } & ASAR & C-SAR \\
\hline Ângulo de Incidência & \multicolumn{4}{|c|}{$20^{\circ}-26^{\circ}$} & $19,2^{\circ}-26,7^{\circ}$ & $29,1^{\circ}-46^{\circ}$ \\
\hline Banda Espectral & \multicolumn{4}{|c|}{$5,66 \mathrm{~cm}$} & $5,62 \mathrm{~cm}$ & $5,55 \mathrm{~cm}$ \\
\hline Resolução Espacial & \multicolumn{4}{|c|}{$26 \times 30 \mathrm{~m}$} & $9 \times 6 \mathrm{~m}$ & $5 \times 20 \mathrm{~m}$ \\
\hline Revisita & \multicolumn{5}{|c|}{35 dias } & 12 dias \\
\hline Órbita & \multicolumn{4}{|c|}{ Descendente } & Ascendente & Descendente \\
\hline Data de Aquisição & $16 / 05 / 1992$ & $27 / 11 / 1993$ & $09 / 04 / 1996$ & $08 / 06 / 1999$ & $28 / 01 / 2006$ & $02 / 05 / 2015$ \\
\hline Chuva 5 dias (mm) & 8,5 & 16,2 & 66,9 & 83,1 & 2,9 & 90,1 \\
\hline Insolação (h) & 7,4 & 9,8 & 4,7 & 5,5 & 8,5 & 2,6 \\
\hline Temperatura $\left({ }^{\circ} \mathrm{C}\right)$ & 27,8 & 28,5 & 32,3 & 26,8 & 28,3 & 25,9 \\
\hline Vento $\left(\mathrm{m}^{\mathrm{s}} \mathrm{s}^{-1}\right)$ & 0,7 & 2,8 & 1,0 & 1,7 & 1,8 & 0,7 \\
\hline Maré (m) & 0,4 & 0,6 & 1,9 & 3,2 & 1,0 & 0,7 \\
\hline Lua (\%) & 99,9 & 97,1 & 66,3 & 35,2 & 1,7 & 97,5 \\
\hline
\end{tabular}

*Fonte: (C) ESA (2014); (ESA, 2015b) 
Os dados auxiliares utilizados foram dados meteorológicos e oceanográficos, imagens ópticas obtidas a partir das plataformas Landsat, pelos sensores OLI (Operational Land Imager) e TM (Thematic Mapper), Modelo Digital de Elevação (MDE) do Shuttle Radar Topography Mission (SRTM) e base cartográfica geomorfológica do IBGE (DHN, 2016; IBGE, 2015; INMET, 2016; USGS, 2015). Os dados meteo-oceanográficas referem-se às datas e horários de aquisição das imagens SAR, utilizados como parâmetros de agrupamento para explicar as diferenças abruptas no retroespalhamento em função da constante dielétrica. As imagens Landsat foram necessárias para a análise da qualidade temática das mudanças costeiras. O mapa geomorfológico foi utilizado na avaliação temática morfológica, enquanto que o SRTM serviu para a geração de produtos ortorretificados, de acordo com a cadeia de processamento SAR em amplitude e descrição dos ambientes costeiros.

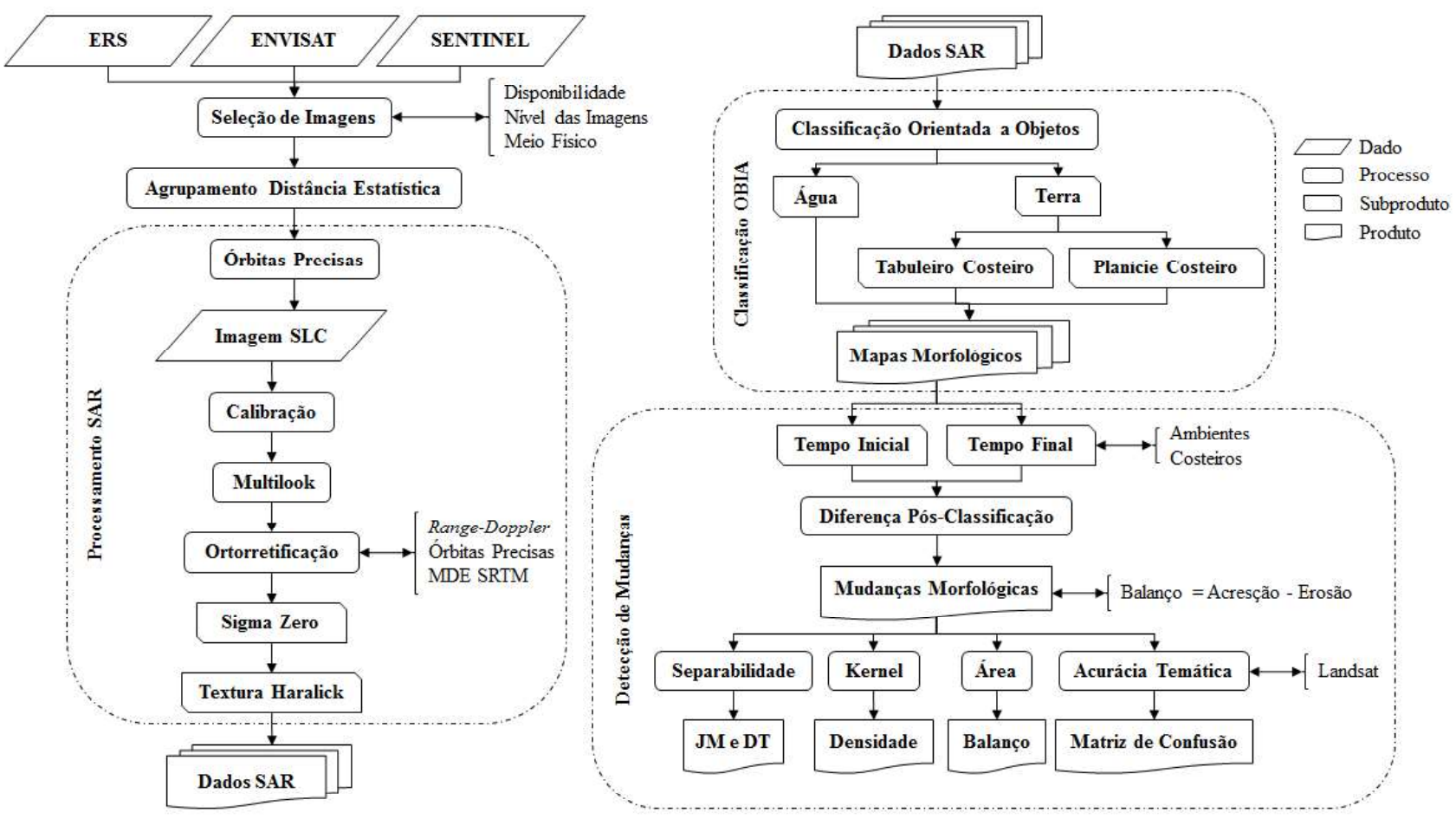

Figura 2 - Fluxograma com os procedimentos executados a partir da obtenção dos dados SAR ERS, ENVISAT e SENTINEL.

\subsubsection{Seleção e Agrupamento de Dados $S A R$}

A comparação de cenas obtidas em condições físicas similares é uma premissa em estudos de detecção de mudança para ambientes costeiros (WANG, 2010). A seleção de imagens ERS, ENVISAT e SENTINEL

\subsection{Abordagem Metodológica}

Os procedimentos para a realização deste estudo (Figura 2) constaram basicamente de: i) delinear a área experimental para o perfil temporal de dados $S A R$; ii) executar a cadeia de processamento $S A R$ em amplitude, para obter dados calibrados e geocodificados, conforme a abordagem descrita por Ferretti et al. (2007); iii) aplicar classificação orientada a objetos para discriminar ambientes costeiros e posterior detecção de mudanças, conforme proposto por Blaschke (2010) e Lu et al. (2004); iv) realizar análises estatísticas para avaliar a separabilidade entre as classes definidas e validar a classificação, seguindo a metodologia proposta por Congalton e Green (2009) e Johnson e Wichern (2007). Os tratamentos aplicados aos dados $S A R$ foram executados no aplicativo gratuito Sentinel-1 Tool Box (S1TBX), desenvolvido pela ESA (ESA, 2014). A classificação das imagens com suporte de dados auxiliares e a avaliação da acurácia temática foram desenvolvidas no aplicativo Ecognition Developer 8, da Universidade Estadual Paulista "Júlio de Mesquita Filho" (UNESP), Campus de Presidente Prudente. 
para um dado instante, em condição de passagens múltiplas sob a perspectiva de deteç̧ão de mudanças. Além disto, o nível de processamento $S L C$ foi estabelecido como pré-requisito, por possibilitar acesso aos dados reais e imaginários, com resolução espacial plena para alcance e azimute, o que possibilitou tratá-los com amostragens diferenciadas para a redução de efeito speckle.

Com base nas características da costa amazônica observadas por Nittrouer et al. (1995), as aquisições $S A R$ foram determinadas em períodos de descarga hídrica próximos, cujas mínimas ocorreram em novembro, e máximas em maio. O tratamento das cenas $S A R$ foi executado para o nível calibrado em radiometria e ortorretificado, assegurando a comparação das células de resolução em posição e valor de sinal. Em consonância, foram observadas as variáveis do meio físico como precipitação, ventos, maré, ciclo lunar e temperatura, responsáveis por alterar a resposta do ambiente costeiro para o retroespalhamento detectado pelo sistema SAR (SOUZA-FILHO et al., 2011; WANG, 2010). Desta forma, optou-se pelo agrupamento das imagens $S A R$ segundo as informações data de aquisição das cena, precipitação, temperatura, vento, maré e ciclo lunar, as quais estão listadas na Tabela 1 . $\mathrm{O}$ agrupamento estatístico realizado se baseou na distância estatística de Manhattan, que estima uma distância absoluta com menor influência de outliers para análise da similaridade (JOHNSON; WICHERN, 2007).

\subsubsection{Cadeia de Processamento $S A R$ em Amplitude}

Os vetores de estado dos satélites foram corrigidos pelos algoritmos Delft e precise sentinel, implementados no S1TBX, os quais estimam efemérides precisas (posição, velocidade e atitude), e assim permitem uma determinação posicional consistente na execução dos procedimentos de co-registro e geocodificação no nível de subpixel (MURA, 2001; REIGBER et al., 1996). Para haver comparabilidade entre os níveis de cinza de diferentes aquisições $S A R$, optou-se pela calibração radiométrica com obtenção do coeficiente de retroespalhamento ou sigma zero $\left(\sigma^{0}\right)$ em unidade logarítmica de decibéis $(\mathrm{db})$ (WOODHOUSE, 2006).

Para minimizar o efeito speckle, utilizou-se o processamento multilook, com filtro modificado de Lee, o qual suaviza as variações tonais cena, preservando bordas e feições agudas (LEE; POTTIER, 2009). A janela móvel aplicada teve dimensão $7 \times 7$ e limiar de variabilidade de 5.000, sendo geradas imagens entre 5 a 6 looks. $O$ processamento multilook consistiu na reamostragem das imagens $S A R$ para as direções de alcance e azimute, com detrimento da resolução espacial e suavização da radiometria, preferencialmente resultando em um pixel final quadrado (ESA, 2014; HENDERSON; LEWIS, 1998). A ortorretificação ocorreu por meio das equações Range-Doppler, que permitem corrigir posições (x, y e z) e distorções geométricas intrínsecas da projeção em alcance inclinado para a projeção no terreno, considerando para tal, o vetor de estado da plataforma (trajeto e atitude), a cadência Doppler do sinal SAR e o MDE (GOBLIRSCH; PASQUALI, 1996; SCHREIER, 1993). O MDE do SRTM está disponível pela USGS (2015) em cobertura global com 30 metros de resolução espacial e $1 \mathrm{~m}$ de resolução vertical, este foi aplicado no processo de ortorretificação que considerou ainda a reamostragem por interpolação bilinear com relação de 5 a 6 looks em azimute para cada 1 em alcance, resultando em aproximadamente $20 \mathrm{~m}$ de resolução no terreno.

$\mathrm{O} \sigma^{0}$ foi a informação espectral primária comparável ao longo do tempo e usada no reconhecimento dos ambientes costeiros. Essa grandeza está diretamente relacionada com o sinal proveniente da célula de resolução normalizada da superfície terrestre e denota mecanismos de espalhamento superficial, volumétrico ou dupla reflexão, formas geométricas como esfera, dipolo e triedro e diferentes conteúdos de umidade. Permite, desse modo inferir os mecanismos de espalhamento predominantes em todo o intervalo espectral analisado (WOODHOUSE, 2006). Para aumentar a dimensionalidade dos atributos analisados, foram gerados a matriz de co-ocorrência de níveis de cinza (Gray Level Co-occurrence Matrix GLCM) e o coeficiente de variação (CV). A GLCM ou Haralick é uma indexação para a textura, resultante de combinações entre escalas de cinza, dadas pela variabilidade da cena ao longo de uma direção de observação (HARALICK et al., 1973). O CV mede o impacto do desvio padrão na média, ajudando a entender o sinal e o ruído em termos de dispersão (LEE; POTTIER, 2009). Neste caso, o GLCM e CV resultaram da aplicação de janelas móveis de 9x9 em todas as direções, realçando características das unidades morfológicas em extensão, sem degradar bordas que são imperceptíveis para os dados em análise monocromática e $S L C$.

Dois mecanismos foram usados para análise a qualidade dos dados SAR: o número equivalente de looks (NEL) e coeficiente de variação (CV). A importância da utilização do NEL é que este fornece uma medida 
qualitativa da relação sinal/ruído que denota áreas homogêneas de correlação espacial, útil em modelos estatísticos de formação e para o pós-processamento $S A R$, ao medir arranjos de sinais independentes contidos na cena (WOODHOUSE, 2006). Em adição, foi utilizado o CV, que caracteriza o impacto do desvio sobre a média, e auxilia o entendimento do sinal e do ruído (LEE; POTTIER, 2009).

\subsubsection{Classificação dos Ambientes Costeiros}

O mapeamento consistiu em discriminar ambientes costeiros terrestres (Tabuleiro Costeiro e Planície Costeira) e água, já que imagens de radar definem melhor informações espaciais relacionadas ao relevo, expressas principalmente pelas variações de textura, e que tornam as abordagens orientadas a objeto adequadas para distinguir feições florestais e não florestais (MITCHELL et al., 2014). Desta forma, utilizou-se classificação orientada a objetos com algoritmos de segmentação multiresolution e classificação baseada em regras (TRIMBLE, 2014). A segmentação multiresolution gerou regiões pela fusão de elementos espacialmente próximos, unidos segundo critérios de homogeneidade (cromaticidade e forma), considerando um limiar de escala como parâmetro de solução (BAATZ; SCHÄPE, 2000; REJAUR RAHMAN; SAHA, 2008). O classificador baseado em regras rotulou as regiões, usando um limiar booleano aplicado ao atributo numérico considerado, segundo uma abordagem de herança e hierarquia, definida, neste estudo, em chave de interpretação (TRIMBLE, 2014).

Na segmentação foi utilizado um parâmetro de escala de 200, homogeneidade baseada em forma com valor 0,8 e compacidade de 0,5 , produzindo-se objetos homogêneos de maior tamanho, orientados preferencialmente pela forma em detrimento da informação espectral, considerando a finalidade de mapeamento morfológico dos ambientes costeiros (NAPIERALSKI et al., 2013). Executou-se a classificação hierárquica por meio de regras específicas e únicas aos conjuntos de dados baseadas nos atributos procedentes de índices espectrais, texturais, geométricos e relações de vizinhança (HUSSAIN et al., 2013). A reclassificação foi aplicada posteriormente, sendo que a primeira iteração por classe e consistiu em aprimorar a classificação por operadores lógicos (Tabela 2). Por se tratar de um ambiente sujeito a dinâmica de maré, a ambiguidade espectral em polarização única $S A R$, em função do speckle e feições morfológicas sutis, decorrentes de planícies fluviomarinhas sinuosas, canais de maré, deltas de marés, entre outros, foram discriminados apenas em abordagens por contexto e padrão (ARNESEN et al., 2013).

Os dados $S A R$ da ESA foram usados na elaboração dos mapas morfológicos para as respectivas datas de aquisição das cenas, e forneceram a base para a análise atual dos ambientes costeiros amazônicos, realizada por meio de imagens SENTINEL-1A/2015.

\subsubsection{Análise de Mudanças Costeiras}

Na detecção de mudanças, utilizou-se uma comparação de imagens pós-classificadas e posterior subtração das cenas classificadas (LU et al., 2004). Realizou-se uma suavização das classificações individuais, por meio de uma janela móvel 3x3, considerando que feições de pequena dimensão não constituíam contribuições significativas ou erros provenientes da variação posicional das células de resolução, semelhante as abordagens de França e Souza-filho (2003) e Souza Filho et al. (2006). A unidade mínima de mapeamento para os dados $S A R$ foi de 3,6 hectares.

A subtração entre as cenas dos estágios inicial e final mostrou feições em que a classe água foi modificada para classe terra, sendo essas consideradas como áreas de acresção, já que nelas ocorrem deposição de sedimentos predominantemente lamosos na planície de maré. Nesses ambientes é possível verificar o desenvolvimento de manguezais, restingas, deltas de maré vazante e cordões praiais (RODRIGUES; SOUZA-FILHO, 2011; SOUZA FILHO et al., 2006). O segundo tipo de representação de mudança consistiu em feições da classe terra que se tornaram água, consideradas como áreas de erosão, que ocorrem em função do recuo da linha de costa, tanto na planície costeira como no tabuleiro costeiro e estão relacionadas à hidrodinâmica local, sendo intensificadas por forçantes físicas locais como ondas, marés, ventos e/ ou tempestades (EL-ROBRINI et al., 2006; FRANÇA; SOUZA-FILHO, 2003).

O quantitativo das feições de acresção subtraído do quantitativo das áreas de erosão, para um par de imagens $S A R$ de datas extremas, produziu o indicativo do balanço sedimentar por unidade de área, além da respectiva taxa de variação anual. Para determinar diferenças estatísticas significantes, utilizou-se o teste $t$-Student, com nível de confiança de $95 \%$ aplicado as amostras de balanço sedimentar, sendo que amostras com $p$-valor maior que 0,05 foram consideradas iguais. 
Tabela 2: Processos e regras de classificação para o mapeamento dos ambientes costeiros amazônicos.

\begin{tabular}{|c|c|c|c|c|}
\hline Processo & Subprocesso & Algoritmo & Classe & Regra/Parâmetro $^{1}$ \\
\hline Segmentação & - & Multiresolution & Todas & $\begin{array}{c}\text { Escala } 200 \\
\text { Forma } 0,8 \\
\text { Compacidade } 0,5 \\
\end{array}$ \\
\hline \multirow{4}{*}{ Classificação } & \multirow{2}{*}{$\begin{array}{l}\text { Classificação } \\
\text { Água/Terra }\end{array}$} & \multirow{2}{*}{ Assign Class } & Água & $\begin{array}{c}\text { Sigma Zero } \leq-7,1 \\
\text { GLCM Desvio } \leq 3600 ; \geq 5070 ; \\
\text { GLCM Homogêneo } \geq 0,19 \\
\text { Índice de Forma } \geq 3,5 \\
\text { Comprimento/Largura } \geq 3,2\end{array}$ \\
\hline & & & Terra & $\begin{array}{c}\text { Sigma Zero } \leq-8 ; \geq-2 \\
\text { GLCM Desvio } \leq 1240 ; \geq 4290 \\
\text { GLCM Homogêneo } \leq 0,14 \\
\text { Índice de Forma } \leq 4,1 ; \geq 2,9\end{array}$ \\
\hline & \multirow{2}{*}{$\begin{array}{l}\text { Classificação } \\
\text { Tabuleiro/Planície }\end{array}$} & \multirow{2}{*}{ Assign Class } & Tabuleiro & $\begin{array}{c}\text { Sigma Zero } \leq-10 \\
\text { GLCM Desvio } \leq 1240 \\
\text { Índice de Forma } \leq 2,9 \\
\text { Borda com Água } \leq 0,5\end{array}$ \\
\hline & & & Planície & $\begin{array}{c}\text { Índice de Forma } \geq 2,9 \\
\text { GLCM Desvio } \geq 4290 \\
\text { Borda com Tabuleiro } \leq 0,5 \\
\text { Borda com Água } \geq 0,5\end{array}$ \\
\hline \multirow[b]{2}{*}{ Reclassificação } & \multirow{2}{*}{$\begin{array}{c}\text { Reclassificação } \\
\text { Água/Tabuleiro/Planície }\end{array}$} & Assign Class & Água & $\begin{array}{c}\text { Borda com Água } \geq 0,5 \\
\text { Borda com Planície } \geq 0,5\end{array}$ \\
\hline & & Assign Class & Tabuleiro & $\begin{array}{c}\text { Borda com Terra } \geq 0,5 \\
\text { Borda com Nenhum } \geq 0,5 \\
\text { GLCM Desvio } \leq 1240 ; \geq 4290\end{array}$ \\
\hline
\end{tabular}

A mesma operação foi realizada para a localização e quantificação de mudanças costeiras entre os dois grupos de similaridade, ao considerar feições de acresção e erosão, sendo que a ocorrência dos eventos de mudanças costeiras foi obtida do centróide das feições. Para a espacialização desses fenômenos, foi usado o estimador de densidade Kernel, que calcula a magnitude de uma feição pontual ou linear por unidade de área ponderado por uma função Kernel e uma regra de suavização e ajuste (MAGUIRE et al., 2005). Foi utilizado o raio de vizinhança no interpolador de $2,5 \mathrm{~km}$, em função da extensão dos pontos de entrada estar em aproximadamente $100 \mathrm{~km}$ (largura de faixa das cenas $S A R$ ).

\subsubsection{Análise da Qualidade}

Para avaliar o desempenho do classificador e a acurácia do mapeamento morfológico costeiro, foram aplicadas abordagens estatísticas baseadas nas medidas de distância ou similaridade de Jeffries-Matusita (JM) e Divergência Transformada (DT) e na Matriz de
Confusão. As distâncias JM e DT funcionam de forma complementar, pois estes coeficientes comparam a separabilidade entre um par de classes em $n$-dimensões de atributos $(1=1,2,3, \ldots, \mathrm{L})$, por meio da estimativa da função densidade de probabilidade normal (RICHARDS; JIA, 2006). Ambos coeficientes variam de 0 a 2 , em que valores maiores que 1,8 são bastante distintos e valores abaixo de 1,0 devem ser desconsiderados ou agrupados em uma única classe. A estatística JM foi utilizada, pois permite avaliar a diferença (distância) entre duas funções densidade de probabilidade normal, associadas à duas classes por meio da distância de Bhattacharyya, a partir dos vetores média e matrizes de covariância das duas classes que estão sendo avaliadas.

A matriz de confusão serviu como subsídio para análise da acurácia das classificações. De acordo com Congalton e Green (2009), essa matriz consiste da tabulação entre amostras de elementos preditos (classificados) e observados (referência) com a constatação de comparação correta para um conjunto de categorias possíveis, oferecendo uma medida da efetividade do 
modelo e permitindo calcular índices como o coeficiente de Kappa o qual mede a probabilidade de concordância e expectativa de discordância entre classes e uma referência de erro controlado ou conhecido.

As feições de ambientes costeiros e mudanças costeiras foram avaliadas para um espaço de atributos formado por três planos de informação: o coeficiente de retroespalhamento, textura baseada no desvio padrão e textura baseada na homogeneidade. Para a análise da acurácia temática, utilizou-se como referência o mapa geomorfológico do IBGE na escala original de 1:250.000 e os dados multiespectrais ortorretificados dos sensores OLI e TM/Landsat, com cobertura de nuvens inferior a 20\%, entre os anos de 1991 e 2014. Os pontos de controle foram obtidos por uma amostragem estratificada aleatória para $5 \%$ do conjunto inicial de pixels.

\section{Resultados e Discussões}

4.1 Seleção das Imagens e Agrupamento por Similaridade

A distância estatística de Manhattan entre conjuntos formados por imagens SAR ERS, ENVISAT e SENTINEL, com base em atributos como data de aquisição das cena, precipitação, temperatura, vento, maré e ciclo lunar, teve a finalidade de minimizar o efeito de outliers (JOHNSON; WICHERN, 2007). Uma vez que essa técnica de agrupamento multivariada requer a definição de grupos prévios, optou-se pelas cinco cenas iniciais como grupos distintos, a partir da primeira data de aquisição $S A R$, com o ERS-1 em 16/05/1992. A distância média entre os grupos foi de 2,17 e máxima de 2,87, resultando em dois grupos finais: i) grupo 1 , contendo dados tomados em condição de maré baixa de sizígia (ERS-1/1992, ERS-1/1993, ENVISAT/2006 e SENTINEL-1A/2015); e, ii) grupo 2, reunindo aqueles obtidos em condição de maré preamar a intermediária em quadratura (ERS-2/1996 e ERS-2/1999) (Figura 3). Esse agrupamento temporal se fez necessário, pois a comparação de imagens só ocorre em mesma condição de maré e ciclo lunar, face a amplitude da onda de maré ( 2 a $5 \mathrm{~m}$ ) e a diversidade de formações litorâneas sujeitas a influência de maré como sistemas praiais de barras e calhas, deltas, canais de maré e planícies, conforme mostram os estudos de França e Souza Filho (2003), Santos (2006) e Souza Filho et al. (2006). A abordagem por agrupamentos de imagens e variáveis foi importante por associar processos costeiros erosivos ou acrescionais às variáveis meteo-oceanográficas e a sazonalidade como reportado em Muehe (2006b), Muehe et al (2015), Santos e Amaro (2013) e Santos et al. (2014).

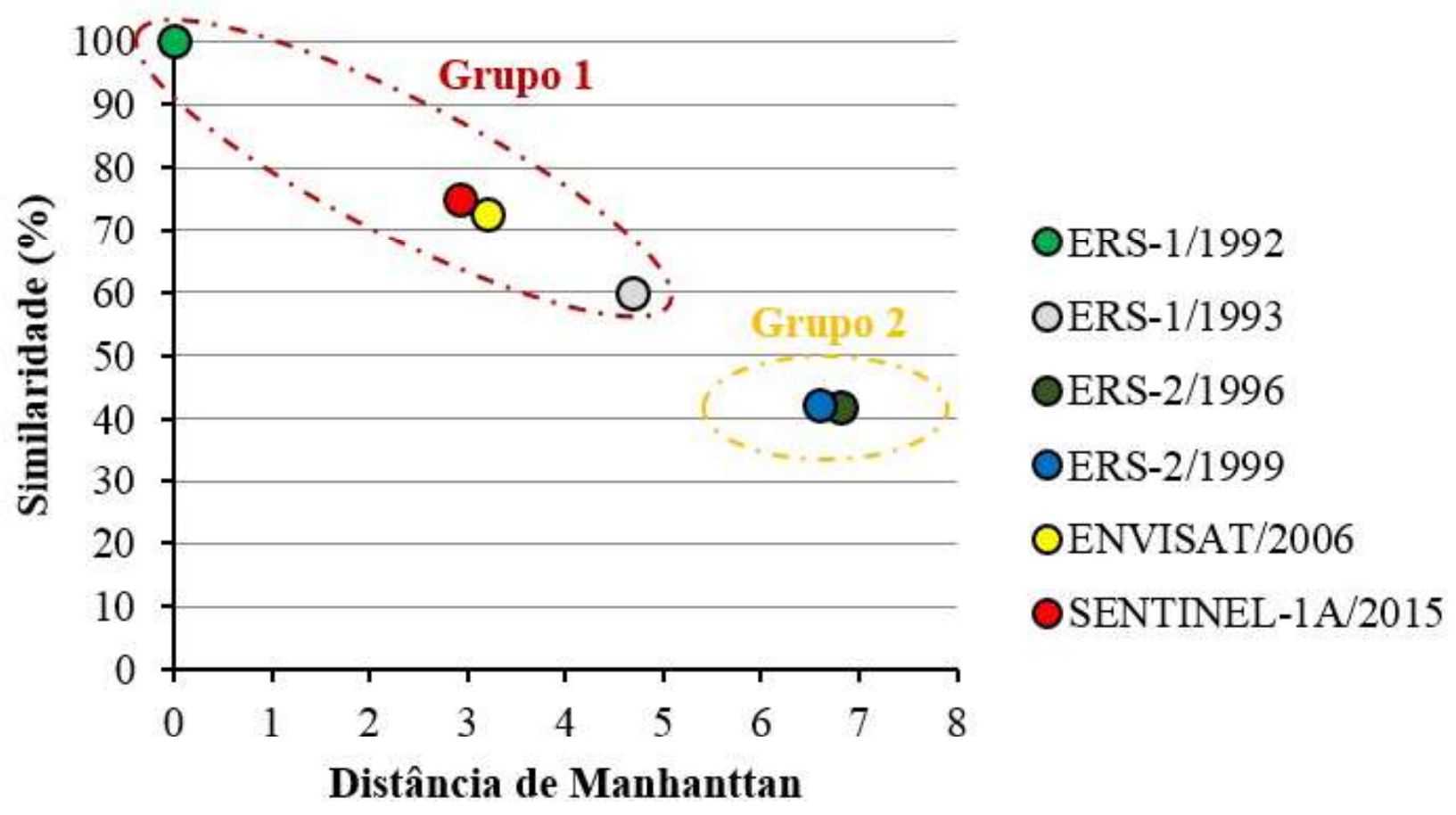

Figura 3 - Agrupamento das cenas $\boldsymbol{S A R}$ com base na similaridade nas características fisicico-ambientais no momento de aquisição das imagens. 
Os resultados comprovam a pequena chance de encontrar pares de imagens $S A R$ em idêntica geometria de aquisição, para a mesma órbita e trajeto, caracterizadas por menor descorrelação espacial, temporal e em sinal. Ao longo dos anos em que se dispõe de imagens obtidas nas missões ERS e ENVISAT, isso ocorreu poucas vezes e é o motivo do baixo número de imagens SAR disponíveis para o litoral norte amazônico.

\subsection{Processamento dos Produtos SAR}

Os dados ERS, ENVISAT e SENTINEL apresentaram um aprimoramento radiométrico gradativo no sinal, o que pode ser verificado ao se observar a variabilidade das cenas, em específico as características das imagens quanto ao CV e NEL. A variabilidade aumentou significativamente a partir da cena ERS-1/1992, partindo de $32 \%$ até $70 \%$ para o SENTINEL-1A/2015. O NEL teve um comportamento oposto, diminuindo no decorrer do tempo. Para o ERS-1/1992, o NEL foi de 9,90 reduzindo para 2,02 no SENTINEL-1A/2015. Assim, o ganho na relação sinal/ruído foi expresso pelo aumento da variabilidade das cenas e pela independência dos elementos retroespalhadores com mais informação no sinal.

Constatou-se que para a área de estudo, com relevo plano a ondulado, amplitude média de $23 \mathrm{~m}$, não foram evidenciadas distorções geométricas severas para ângulos de incidência entre $20^{\circ}$ e $47^{\circ}$, demonstrando que, além dos metadados completos, órbitas precisas são cruciais para aplicação de técnicas que requerem precisão como co-registro entre pilhas de imagens complexas e deteç̧ão de mudanças para produtos ortorretificados por equações Range-Doppler (FERRETTI et al., 2007).

Outra questão preponderante para a análise foi a possibilidade de discriminação das feições nas imagens multitemporais utilizadas. A textura GLCM foi um indicativo importante na caracterização das unidades de relevo, por realçar bordas das feições, haja vista que os dados $S A R$ mais antigos tem polarização plana única em VV, com ângulo de incidência fixo (HEROLD et al., 2004).

A possibilidade de explorar as informações de textura e contexto viabilizaram a discriminação de ambientes costeiras em escalas locais a regionais. Na Tabela 3 são mostradas as imagens resultantes do processamento SAR para dados obtidos pelos três diferentes sistemas e respectivas estatísticas descritivas.

Torres et al., (2012) relataram as possibilidades de aplicações dos dados $S A R$ da ESA, que são sustentadas pelo emprego em condições ambientais adversas, na interoperabilidade do comprimento de onda entre satélites e no desenho orbital das plataformas para revisita em arranjo tandem.

\subsection{Classificação dos Ambientes Costeiros}

Formalizou-se um mecanismo de reconhecimento (chave de interpretação) para mostrar a associação entre as feições na imagem $S A R$ e unidades morfoestruturais extraídas da base vetorial do IBGE, para viabilizar o processo de classificação orientada a objetos (Tabela 4). Para as unidades de relevo identificáveis, descreve-se os aspectos de cor, textura, forma e padrão, e indica-se valores e regras de classificação utilizadas.

A chave de interpretação permite reconhecer pelo menos duas feições por ambiente costeiro, em imagens $S A R$ em banda C com polarização simples (VV). A posteriori, feições costeiras devem ser observadas em campo para aperfeiçoar e avaliar o mapeamento morfológico obtido por dados $S A R$ como nos estudos de Polizel e Rossetti (2014), Rodrigues e Souza-Filho (2011) e Souza-Filho et al. (2011).

O Tabuleiro Costeiro apresentou formas arredondadas extensas, irregulares a regulares e dissecadas. A cobertura da terra variou entre solo exposto, vegetação secundária e formações florestais densas, as quais definiram tons de cinza claro, moderado e escuro com textura variando de liso a rugoso. Essas características reconhecidas nas imagens $S A R$ fazem parte de um relevo de degradação sustentado por rochas sedimentares da formação Barreiras e Pós-Barreiras, sendo que as litologias comuns são arenitos a argilitos (COSTA et al., 1991). Esse ambiente tem cota altimétrica média de 27,38 m e declividade suave ondulada (6,77\%).

A Planície Costeira foi caracterizada por tons de cinza claro a moderado e em formas curvilíneas sinuosas e estreitas variadas nas porções mais continentais. Nas porções fluviomarinhas adjacentes a baía de Macapá, ocorreram formas alongadas, extensas e arredondadas de forte rugosidade. Esse relevo de agradação é constituído por camadas arenosas a argilosas de origem fluviomarinha, com a cadência de inundações controlada pela ação de marés e estações do ano (MATOS et al., 2011). A hidrografia mostrou frequentes desvios de direções e diferentes padrões de drenagens, consistindo em evidência de controle tectônico na sedimentação quaternária, como observado por Souza e Rossetti (2011). A cota altimétrica tem média de 18,34 $\mathrm{m}$ e declividade suave ondulada $(6,41 \%)$. 
Guimarães U. S. et al.

Tabela 3: Estatísticas descritivas e produtos resultantes do processamento SAR dos dados ERS, ENVISAT e SENTINEL.

\begin{tabular}{|c|c|c|c|c|c|}
\hline $\begin{array}{c}\text { Satélite/ } \\
\text { Aquisição }\end{array}$ & Estatísticas & $\begin{array}{c}\text { Nível } \\
\text { Primário }\end{array}$ & Calibração & Geocodificação & Textura \\
\hline $\begin{array}{c}\text { ERS-1 } \\
16 / 05 / 1992\end{array}$ & $\begin{array}{c}\text { Min.:-29,73 } \\
\text { Máx.:21,38 } \\
\text { Média:-8,06 } \\
\text { Desvio:2,56 } \\
\text { CV:-0,32 } \\
\text { NEL:9,90 }\end{array}$ & & & & \\
\hline $\begin{array}{c}\text { ERS-1 } \\
27 / 11 / 1993\end{array}$ & $\begin{array}{c}\text { Min.:-29,44 } \\
\text { Máx.:20,01 } \\
\text { Média:-8,54 } \\
\text { Desvio:2,70 } \\
\text { CV:-0,32 } \\
\text { NEL:9,85 }\end{array}$ & & & & \\
\hline $\begin{array}{c}\text { ERS-2 } \\
09 / 04 / 1996\end{array}$ & $\begin{array}{c}\text { Min.:-31,26 } \\
\text { Máx.:17,62 } \\
\text { Média:-8,14 } \\
\text { Desvio:2,74 } \\
\text { CV:-0,34 } \\
\text { NEL: } 8,80\end{array}$ & & & & \\
\hline $\begin{array}{c}\text { ERS-2 } \\
08 / 06 / 1999\end{array}$ & $\begin{array}{c}\text { Min.:-30,29 } \\
\text { Máx.:26,55 } \\
\text { Média:-7,96 } \\
\text { Desvio:2,70 } \\
\text { CV:-0,34 } \\
\text { NEL:8,68 }\end{array}$ & & & & \\
\hline $\begin{array}{l}\text { ENVISAT } \\
28 / 01 / 2006\end{array}$ & $\begin{array}{c}\text { Min.:-46,34 } \\
\text { Máx.:24,90 } \\
\text { Média:-7,81 } \\
\text { Desvio:2,95 } \\
\text { CV:-0,38 } \\
\text { ENL:6,99 }\end{array}$ & & & & \\
\hline $\begin{array}{l}\text { SENTINEL-1A } \\
02 / 05 / 2015\end{array}$ & $\begin{array}{c}\text { Min.:-56,26 } \\
\text { Máx.:24,43 } \\
\text { Média:-9,46 } \\
\text { Desvio:6,65 } \\
\text { CV:-0,70 } \\
\text { NEL:2,02 }\end{array}$ & 13 & 8 & & \\
\hline
\end{tabular}

Tabela 4: Chave de interpretação elaborada para reconhecer os ambientes costeiros da foz do Amazonas em imagem SAR.

\begin{tabular}{c|c|c|c|c|c|c}
\hline \multirow{2}{*}{$\begin{array}{c}\text { Ambientes } \\
\text { Costeiros }\end{array}$} & \multicolumn{2}{|c|}{ Tabuleiro Costeiro } & \multicolumn{2}{c|}{ Planície Costeira } & \multicolumn{2}{c}{ Drenagens } \\
\cline { 2 - 7 } & S/Vegetação & C/Vegetação & Estreita & Larga & S/Perturbação & C/Perturbação \\
\hline \multirow{2}{*}{$\begin{array}{c}\text { Imagem } \\
\text { SAR }\end{array}$} & & & & & & \\
& & & & & & \\
& & & & & & \\
Cor & Cinza/Escuro & Cinza & Cinza/Claro & Cinza & Cinza/Escuro & Cinza/Escuro \\
\hline Textura & Liso & Rugoso & Rugoso & Rugoso & Liso & Liso/Rugoso \\
\hline Forma & Compacto & Compacto & Irregular/Curvo & Compacto & Irregular & Irregular \\
\hline Padrão & Dissecado & Dissecado & Dendrítico & - & Alongado & - \\
\hline
\end{tabular}


As regras e parâmetros constituíram-se dos atributos de coeficiente de retroespalhamento, desvio padrão GLCM, homogeneidade GLCM e índice de forma. Foram mapeados três ambientes: o Tabuleiro Costeiro com $3.371,45 \mathrm{~km}^{2}$ (50,67\%), a Planície Costeira com 2.296,06 $\mathrm{km}^{2}(34,51 \%)$ e Drenagens com $985,74 \mathrm{~km}^{2}(14,82 \%)$. O Tabuleiro Costeiro foi caracterizado por um coeficiente de retroespalhamento médio de $-7,83$ db e desvio padrão de 2,11 db, a Planície Costeira com média de $-6,60 \mathrm{db}$ e desvio padrão de 2,08 db, e por último, as Drenagens com média de $-19,09 \mathrm{db}$ e desvio padrão de 2,77 db. A intensidade do sinal de retroespalhado no Tabuleiro Costeiro definiu tons de cinza mais escuro do que as feições na Planície Costeira, ambos com caraterísticas heterogêneas, enquanto que as Drenagens apareceram em tom escuro homogêneo, oferecendo boa discriminação visual (Figura 4).

$\mathrm{O}$ coeficiente de retroespalhamento de um alvo da superfície terrestre tem relação intrínseca com o ângulo de incidência local, e consequentemente, afeta o brilho e a capacidade de penetração vertical da onda incidente (NARVAES et al. 2010). Para a cena
SENTINEL-1A/2015, o ângulo de incidência foi considerado rasante $\left(\theta>30^{\circ}\right)$ com média de $42,5^{\circ}$ e desvio padrão de $3,51^{\circ}$. Essa geometria de aquisição melhorou a discriminação entre a parte terrestre e a água em relação às demais imagens analisadas para uma mesma classe, como é perceptível na Figura 4(c). Isso pode ser verificado nas feições de Drenagens que se comportaram de forma mais homogênea, com CV de 14\% e, consequentemente, foram mais discrimináveis. Por outro lado, a maior variabilidade média no coeficiente de retroespalhamento ocorreu para Planície Costeira, com $\mathrm{CV}$ de $31 \%$, o que aponta para uma maior dificuldade de discriminação desse tipo de feição.

Iniciativas anteriores demostraram que a discriminação na planície costeira pode ser obtida pelo uso da banda L, adotando abordagens multissensor com a fusão de dados Alos Palsar e imagens ópticas, aplicadas no mapeamento geomorfológico do delta do rio Doce e estuário do rio Caeté, os quais atingiram desempenho satisfatório observados por Polizel e Rossetti (2014) e Souza-Filho et al. (2011), respectivamente.

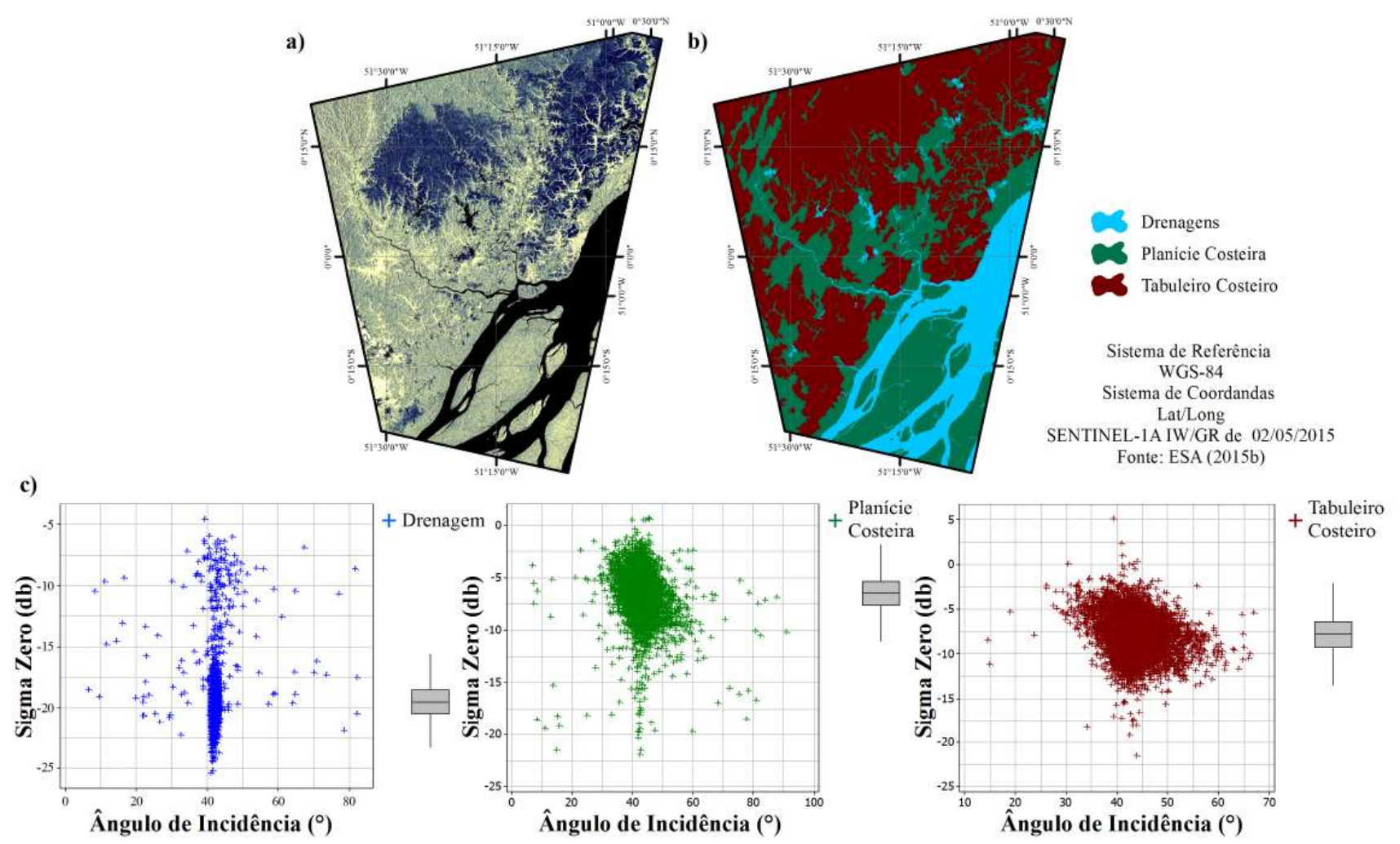

Figura 4 - Ambientes costeiros da foz do Amazonas mapeados a partir de dados SAR ERS-ENVISAT-SENTINEL. a) Imagem do sensor SENTINEL-1A do dia 02/05/2015, em composição colorida R-GLCM média, G-GLCM desvio padrão e B-Sigma Zero da polarização paralela vertical. b) Imagem classificada a partir da chave de interpretação aplicada no processo de classificação orientada a objetos. c) Características do coeficiente de retroespalhamento ao longo do ângulo de incidência local para as classes mapeadas. 


\subsection{Detecção de Mudanças}

As mudanças costeiras foram caracterizadas inicialmente por estatísticas descritivas calculadas para o coeficiente de retroespalhamento e expressas no gráfico mostrado na Figura 5. As feições de acresção possuem maior amplitude média de sinal retroespalhado, menor variabilidade e maior homogeneidade, quando comparadas às feições de erosão. As estatísticas dos dados $S A R$ para o ano 2015, evidenciam o comportamento do sigma zero, diferenciado dos demais por definir valores entre -1 a -9 db. Esse comportamento está relacionado a mudanças no ângulo de incidência local que nos sensores dos siste- mas ERS-1, ERS-2 e ENVISAT foi de 22,15, enquanto que no sensor do SENTINEL-1A, a incidência local foi de $42,67^{\circ}$. A mudança da geometria de aquisição de ângulos mais íngremes $\left(\theta<30^{\circ}\right)$ para ângulos rasantes $\left(\theta>30^{\circ}\right)$ condiciona uma diminuição gradual do sinal retroespalhado na banda $\mathrm{C}$ para acresção e erosão, respectivamente, da ordem de $-0,97 \mathrm{db}$ e $-8,92 \mathrm{db}$. Essa condição é também observada pela tendência evidenciada na Figura 5, para as classes analisadas, o que é corroborados por Narvaes et al. (2010), que constataram tendência no aumento dos valores de $\sigma^{\circ}$, recorrentes nas polarizações $\mathrm{HH}$ e VV em banda $\mathrm{L}$, de maior penetrabilidade.
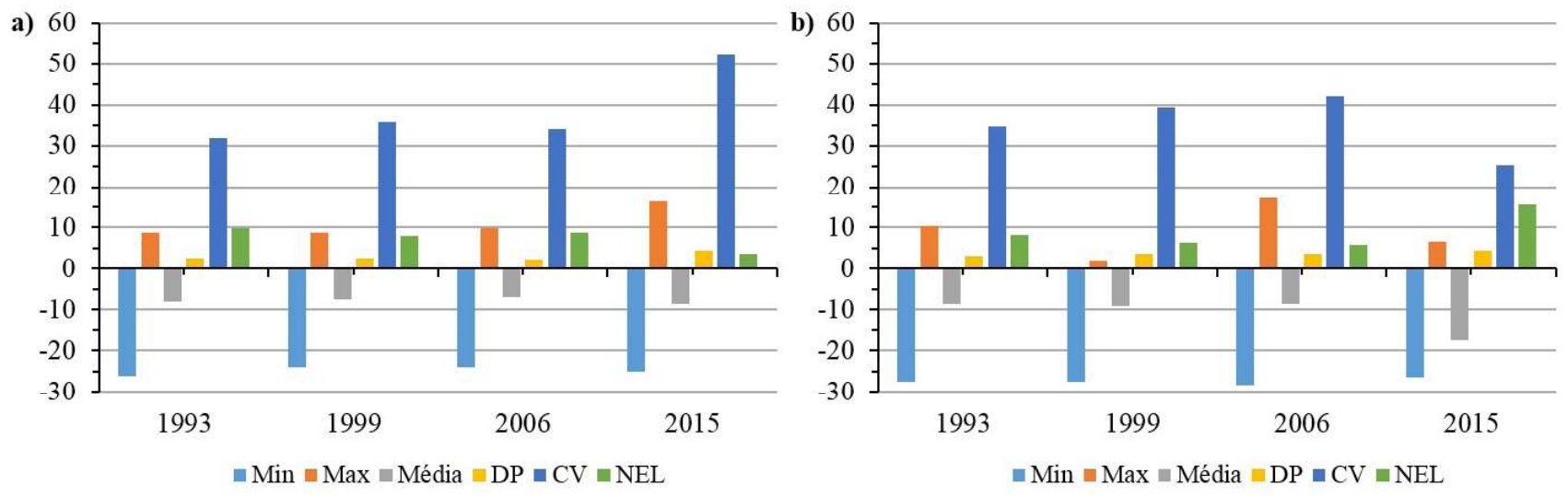

Figura 5 - Estatísticas descritivas para as feições de mudanças costeiras mapeadas como acresção (a) e erosão (b). Min, Max e Média representam os valores de coeficiente de retroespalhamento. DP, CV e NEL são desvio padrão da média de $\sigma^{\circ}$, percentual do coeficiente de variação e número equivalente de looks da imagem, respectivamente.

As mudanças costeiras foram feições sutis que corresponderam a $646,15 \mathrm{~km}^{2}$, ou cerca de $2,44 \%$ de um total mapeado de $26.522,93 \mathrm{~km}^{2}$, entre os períodos de 1992 a 2015. O balanço sedimentar total estimado foi erosivo em $-2,32 \mathrm{~km}^{2}$, a taxa de $-0,10 \mathrm{~km}^{2}$.ano ${ }^{-1}$, o que correspondeu a apenas $0,0092 \%$ do total mapeado. $\mathrm{O}$ perfil temporal de mudanças costeiras constou de dois momentos estatisticamente diferentes para o balanço sedimentar. Aplicando-se o teste $t$-Student ao nível de confiança de 95\% com p-valor das amostras em 0,02, certifica-se que: i) as análises de 1992 a 1993 e 1996 a 1999 apontam para uma condição erosiva em -9,36 $\mathrm{km}^{2} \mathrm{e}-8,98 \mathrm{~km}^{2}$, respectivamente; e, ii) as análises nos períodos de 1993 a 2006 e 2006 a 2015 demostraram condição de acresção em $8,35 \mathrm{~km}^{2}$ e $7,66 \mathrm{~km}^{2}$, respectivamente (Figura 6). Esses indicativos de mudanças costeiras remetem a uma condição geral de equilíbrio na foz do rio Amazonas, marcados pelo período ini- cial de erosão seguido por acresção, como reportado em estudos anteriores de Batista et al., 2009 e Santos (2006). Em adição, sob a perspectiva de escalas espaciais menores, aplicadas a toda área de influência da pluma de sedimentos do rio Amazonas, a tendência em manguezais é acrescional como observado em Gensac et al. (2016) e Nascimento et al. (2013).

Apesar de existirem outras formas de medir o balanço sedimentar com dados remotos e medidas in situ, como em Gensac et al. (2016), Muehe et al. (2015), Santos et al. (2014) e Silva et al. (2016), que contribuíram significativamente para a compreensão do balanço sedimentar, ao relacionar observações de GPS, sazonalidade e variáveis meteo-oceanográficas simultaneamente à aquisição de imagens, MDEs e/ou batimetria, a análise por meio da detecção de mudanças em imagens $S A R$ foi um indicativo satisfatório das mudanças costeiras de erosão e acresção. 


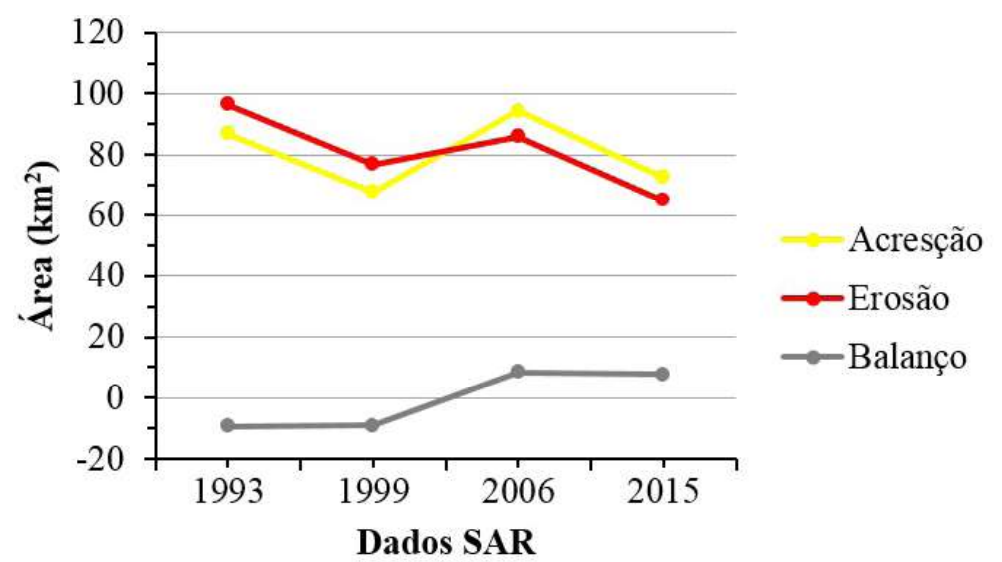

Figura 6 - Perfil temporal de mudanças costeiras a partir de dados SAR em banda C na foz do rio Amazonas.

$\mathrm{Na}$ área de estudo, a condição dos processos erosivos e acrescionais costeiros relacionaram-se à orientação da linha de costa (majoritariamente NE$\mathrm{SW}$ ), às correntes oceânicas, regime de marés e aporte sedimentar proviniente do Amazonas e rios adjacentes. Muehe (2005) afirma que os principais agentes de mudanças costeiras na costa lamosa amazônica são a descarga hídrica/sólida congregada a correntes de maré direcionadas a oceano aberto. Da mesma forma, os estudos de Santos (2006) e de Batista et al. (2009) mencionam porções da costa amazônica com mudança na tendência erosiva nos últimos 30 anos, com franca dinâmica em frentes oceânicas.

As ocorrências de mudanças costeiras encontradas neste estudo estiveram mais presentes nas porções insulares a centro-sudeste e ao longo de drenagens na planície costeira, sobre influência de correntes de maré (fluxo e refluxo). O Tabuleiro Costeiro, mesmo em contato com a frente oceânica a centro-nordeste, apresentou maior resiliência a mudanças costeiras (Figura 7).
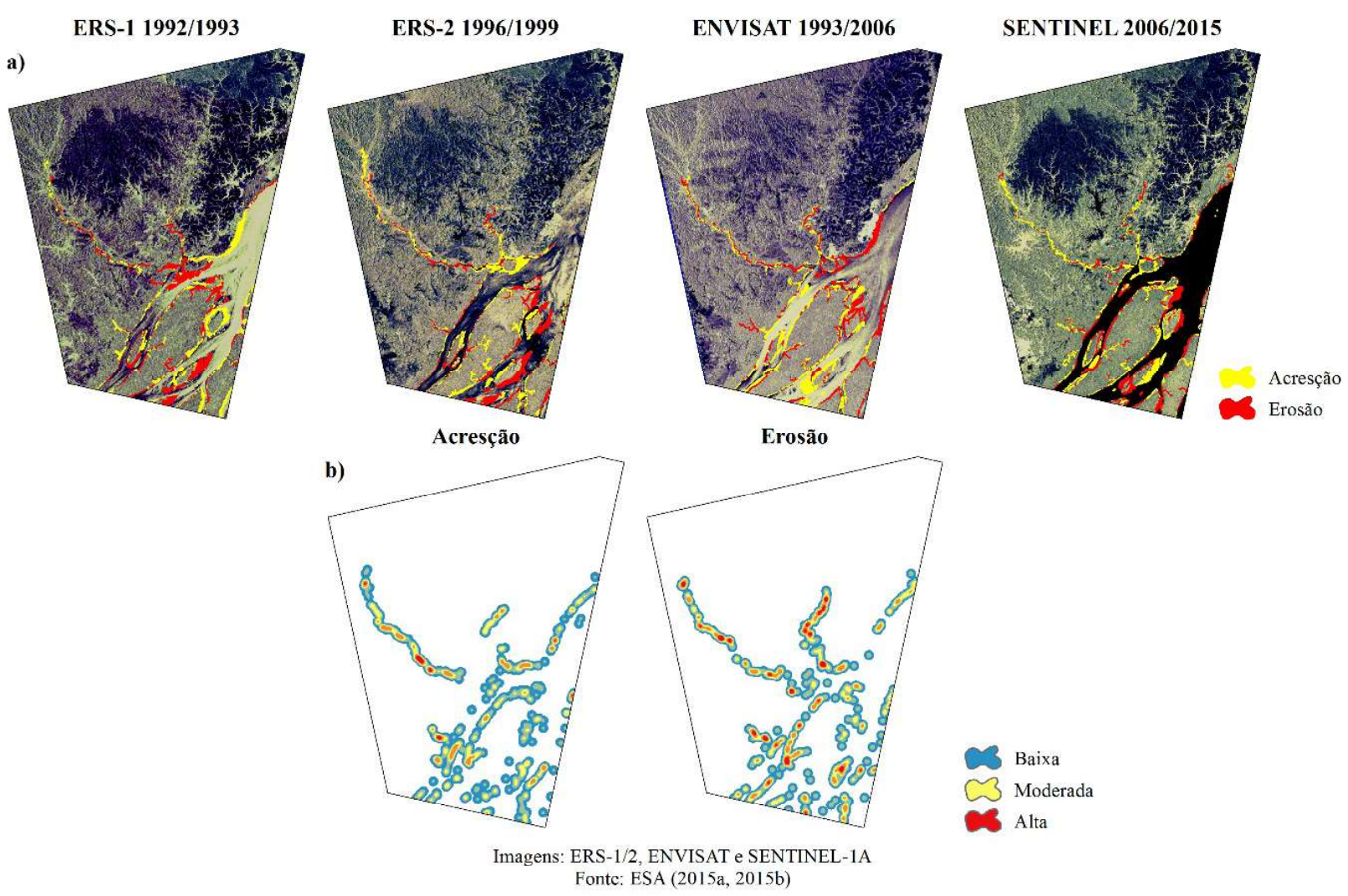

Figura 7 - Mudanças costeiras na foz do Amazonas detectados a partir de dados SAR ERS-ENVISAT-SENTINEL no periodo de 1992 a 2015. a) Áreas de acresção e erosão detectadas ao longo do perfil temporal de dados SAR. b) Densidade de ocorrência dos processos de acresção e erosão. 
Os estudos de Souza-Filho et al. (2011) e Trebossen et al. (2005) corroboram a análise realizada, em que bandas de maior penetrabilidade, como é o caso da banca $\mathrm{C}$ e L em polarização paralela $\mathrm{VV}$, são apropriadas para discriminar terra e água. Todavia, o mapeamento costeiro requer melhorias em escalas espaço-temporais para delineamentos em maior detalhe, o que incluiria a observação de rios e canais em porções continentais sob influência salina e maré, zonas de erosão, deposição efêmera, migração de bancos arenosos e ilhas, deposição lamosa, assoreamento e desenvolvimento de mangues (EL-ROBRINI et al., 2006; MUEHE, 2005). Além disso, deve se obter mais informação quantitativa e qualitativa proveniente da fase interferométrica e polarimétrica, as quais ampliam possibilidades de mapeamento topográfico e discriminação de alvos por meio das técnicas de reconstrução tridimensional da superfície e decomposição polarimétrica, respectivamente (FERRETTI et al., 2007; LEE; POTTIER, 2009).

\subsection{Separabilidade e Acurácia Temática}

A condição de separabilidade das classes a partir dos atributos coeficiente de retroespalhamento e textura GLCM foi confirmada pelos coeficientes JM e DT superiores a 1,9 entre as classes de Drenagens e Planície Costeira e entre Drenagens e Tabuleiro Costeiro, o que demonstrou a eficácia da banda $\mathrm{C}$ co-polarizada na classificação espectral de ambientes úmidos, especificamente entre terra e água, conforme verificado anteriormente por Lang e Kasischke (2008) e Reschke et al. (2012). Os mesmos atributos definiram coeficientes JM e DT inferiores a 1,0 entre as classes de Planície Costeira e Tabuleiro Costeiro, apontando a impossibilidade de separar essas classes e que somente a informação espectral mostrou-se pouco eficaz para solucionar as ambiguidades recorrentes entre as feições segmentadas, o que demandou soluções de classificação por contexto e vizinhança (Tabela 5).

Tabela 5: Matriz de separabilidade dos ambientes costeiros mapeados.

\begin{tabular}{c|c|c|c|c|c|c}
\hline \multirow{2}{*}{$\begin{array}{c}\text { Matriz de } \\
\text { Separabilidade }\end{array}$} & \multicolumn{6}{c}{ Ambientes Costeiros } \\
\cline { 2 - 7 } & \multicolumn{2}{|c|}{ Drenagem } & \multicolumn{2}{c}{$\begin{array}{c}\text { Planície } \\
\text { Costeira }\end{array}$} & \multicolumn{2}{c}{$\begin{array}{c}\text { Tabuleiro } \\
\text { Costeiro }\end{array}$} \\
\cline { 2 - 7 } JM & DT & JM & DT & JM & DT \\
\hline Drenagem & - & - & 1,98 & 1,99 & 1,92 & 1,98 \\
\hline Planície Costeira & 1,98 & 1,99 & - & - & 0,45 & 0,53 \\
\hline Tabuleiro Costeiro & 1,92 & 1,98 & 0,45 & 0,53 & - & - \\
\hline
\end{tabular}

Para feições indicadoras de mudanças costeiras, a separabilidade entre os ambientes, por meio dos atributos definiu coeficientes JM e DT em torno de 1,0, para as feições de acresção e erosão (Tabela 6). Isso se justifica, pois como em Boak e Turner (2005) e Ghoneim et al. (2015), esse tipo de feições ocorrem, em sua grande maioria, nas regiões limítrofes entre ambientes costeiros.

Os resultados obtidos já eram esperados, pois em seus estudos, Nascimento et al., (2013), Santos (2006), Souza-Filho et al. (2011) verificaram que, para mapear linhas de costa, as fontes de informação em microondas precisam ser ampliadas para a banda $\mathrm{L}$, em condição polarimétrica, com uso do sinal complexo em amplitude e fase. O comprimento de onda da banda $\mathrm{L}$ tem maior penetrabilidade na vegetação e apresenta menor saturação para a biomassa em florestas densas e manguezais recursivos, oferecendo maior discriminação de ambientes costeiros amazônicos. Qi et al. (2015) demonstraram que técnicas de detecção de mudanças com utilização de imagens $S A R$ multitemporais (compilação de cenas em passagem repetida), filtradas e co-registradas no nível de subpixel, são capazes de admitir tênues mudanças no sinal em amplitude e fase e detectar feições de mudanças costeiras sutis.

Tabela 6: Matriz de separabilidade das mudanças costeiras mapeadas.

\begin{tabular}{c|c|c|c|c}
\hline \multirow{2}{*}{$\begin{array}{c}\text { Matriz de } \\
\text { Separabilidade }\end{array}$} & \multicolumn{3}{|c}{ Mudanças Costeiras } \\
\cline { 2 - 5 } & \multicolumn{2}{|c|}{ Acresção } & \multicolumn{2}{c}{ Erosão } \\
\cline { 2 - 5 } & JM & DT & JM & DT \\
\hline \hline Acresção & - & - & 0,87 & 1,04 \\
\hline Erosão & 0,87 & 1,04 & - & - \\
\hline
\end{tabular}


Já as condições de separabilidade entre as áreas terrestres e drenagens foram consideradas excelentes $(\mathrm{JM}=[1,92 ; 1,98] ; \mathrm{DT}=[1,98 ; 1,99]$ entre Drenagem e Tabuleiro Costeiro e Drenagem e Planície Costeira, respectivamente), por haver pouca ambiguidade na resposta desses alvos. Por outro lado, os mecanismos de retroespalhamento são diferenciados em ângulos de incidência íngreme $\left(\theta<30^{\circ}\right)$ a rasante $\left(\theta>30^{\circ}\right)$, para feições de água e terra com cobertura vegetal, predominando os mecanismos de espalhamento superficial com característica especular e espalhamento volumétrico, respectivamente. Isso é representado pelos valores de $\sigma^{\circ}$ de $-7,75 \mathrm{db}$ para terra com cobertura vegetal $\mathrm{e}-10,96 \mathrm{db}$ para água. Nesta frequência estudada, existem estudos similares para mapear zonas úmidas vegetadas como aqueles de Furtado et al. (2016) e Kumar e Patnaik (2013), os quais ratificam o uso de sigma zero, textura e polarimetria completa, encontrando similar patamar de discriminação entre feições de água e floresta.

O mapeamento dos ambientes costeiros obteve desempenho muito bom, com exatidão global de $78,35 \%$ e coeficiente Kappa de 0,65, adotando como referência os mapas vetoriais geomorfológicos do IBGE (2004), adequados a escala de 1:250.000. O melhor desempenho foi encontrado para a classe Drenagens, com acurácia do produtor de $94,76 \%$ (erro de omissão igual a 5,24\%), enquanto que o pior resultado foi obtido para Planície Costeira, com acurácia do usuário de 70,74\% (erro de comissão de 29,71\%). A maior confusão temática ocorreu entre a Planície Costeira e Tabuleiro Costeiro, ao se observar os demais erros de comissão e omissão (Tabela 7).

A acurácia temática do mapeamento das mudanças costeiras pode ser qualificada como razoável, com exatidão global de 48,54\% e coeficiente Kappa de 0,32, adotando-se como referência imagens TM/Landsat-5 e OLI/Landsat-8. O melhor desempenho ocorreu para feições de acresção, com acurácia do produtor igual a $79,49 \%$ (erro de omissão de $20,51 \%$ ) e o pior desempenho foi para erosão, com acurácia do usuário de 41,89\% (erro de comissão de 58,47\%). A maior confusão temática ocorreu entre acresção e áreas estáveis, ao se observar os erros de comissão e omissão (Tabela 8).

Tabela 7: Matriz de Confusão para o mapeamento de ambientes costeiros por meio dos dados $S A R$.

\begin{tabular}{c|c|c|c|c|c|c}
\hline \multicolumn{7}{c}{ Ambientes Costeiros x Base de Geomorfologia IBGE (2004) } \\
\hline Matriz de Confusão & $\mathbf{P C}$ & $\mathbf{D r}$ & TC & $\sum$ Linha & $\begin{array}{c}\text { Erro de } \\
\text { Comissão }\end{array}$ & $\begin{array}{c}\text { Acurácia do } \\
\text { Usuário }\end{array}$ \\
\hline Planície Costeira (PC) & $\mathbf{3 7 6 7}$ & 103 & 1489 & 5359 & $29,71 \%$ & $70,29 \%$ \\
\hline Drenagens (Dr) & 228 & $\mathbf{2 1 7 2}$ & 68 & 2468 & $11,99 \%$ & $88,01 \%$ \\
\hline Tabuleiro Costeiro (TC) & 1326 & 13 & $\mathbf{5 7 7 1}$ & 7110 & $18,83 \%$ & $81,17 \%$ \\
\hline Não Classificado (NC) & 4 & 4 & 1 & 9 & & \\
\hline E Coluna & 5325 & 2292 & 7329 & 14946 & & \\
\hline Erro de Omissão & $29,26 \%$ & $5,24 \%$ & $21,26 \%$ & & & \\
\hline Acurácia do Produtor & $70,74 \%$ & $94,76 \%$ & $78,74 \%$ & & & \\
\hline
\end{tabular}

Tabela 8: Matriz de Confusão para mapeamento de mudanças costeiras por meio dos dados SAR.

\begin{tabular}{c|c|c|c|c|c|c}
\hline \multicolumn{7}{c}{ Mudanças Costeiras x Landsat 5 e 8 } \\
\hline Matriz de Confusão & $\mathbf{A c}$ & $\mathbf{A E}$ & $\mathbf{E r}$ & $\sum$ Linha & $\begin{array}{c}\text { Erro de } \\
\text { Comissão }\end{array}$ & $\begin{array}{c}\text { Acurácia do } \\
\text { Usuário }\end{array}$ \\
\hline Acresção (Ac) & $\mathbf{6 2}$ & 56 & 30 & 148 & $58,11 \%$ & $41,89 \%$ \\
\hline Áreas Estáveis (AE) & 16 & $\mathbf{1 9 4}$ & 46 & 256 & $24,21 \%$ & $75,78 \%$ \\
\hline Erosão (Er) & 0 & 37 & $\mathbf{1 0 7}$ & 144 & $25,69 \%$ & $74,31 \%$ \\
\hline$\sum$ Coluna & 78 & 287 & 183 & 548 & & \\
\hline Erro de Omissão & $20,51 \%$ & $32,40 \%$ & $41,53 \%$ & & & \\
\hline Acurácia do Produtor & $79,49 \%$ & $67,60 \%$ & $58,47 \%$ & & & \\
\hline
\end{tabular}

Estudos de Nascimento et al. (2013), SouzaFilho et al. (2011) e Teixeira (2011) que resultaram no mapeamento geológico-geomorfológico da costa amazônica alcançaram coeficientes Kappa entre 0,66 a
0,91, utilizando dados $S A R$ com diferentes incidências e polarização completa, em composição com informações auxiliares provenientes de imagens ópticas. De fato, neste estudo há uma queda na acurácia temática, com 
coeficientes Kappa entre 0,32 a 0,65, fato este atribuído a uma abordagem por dados $S A R$ monocromáticos de polarização simples em incidências íngremes a rasantes tratadas apenas em amplitude.

\section{Conclusões}

Este estudo contribui apresentando uma abordagem para mapeamentos morfológicos e detecção de mudanças na Zona Costeira Amazônica, baseado em dados $S A R$ de amplitude na banda $\mathrm{C}$, para um período de 24 anos. Especificamente no estudo de caso desenvolvido, esta abordagem alcançou desempenho satisfatório para a discriminação, mapeamento e deteç̧ão de mudanças dos ambientes costeiros.

Os dados ERS, ENVISAT e SENTINEL provenientes da ESA propiciaram aquisições similares em comprimento de onda e geometria, o que permitiu tratar as imagens $S A R$ em amplitude, com plena aplicabilidade ao mapeamento morfológico costeiro. $\mathrm{O}$ tratamento por calibração, filtragem, geocodificação, textura extraída de GLCM e classificação orientada a objetos demonstrou ganho qualitativo na análise da variabilidade do sinal e controle da acurácia posicional, o que permitiu aprimorar a discriminação de ambientes costeiros tropicais úmidos.

A separabilidade das classes por meio dos atributos $S A R$ foi considerada boa entre as unidades morfológicas da Planície Costeira e Tabuleiro Costeiro em relação a Drenagens. Entretanto, entre Planície Costeira e Tabuleiro Costeiro e ainda entre a acresção e erosão, houve pouca separabilidade e, portanto, dificuldade de discriminação.

Quanto a acurácia temática, enfatiza-se três aspectos dos ambientes costeiros: i) o conjunto de regras e parâmetros da classificação orientada a objetos conseguiu mapear as classes de Planície Costeira, Tabuleiro Costeiro e Drenagens com bom desempenho para o coeficiente Kappa; ii) a caracterização espectral das classes por meio do coeficiente de retroespalhamento melhorou a identificação dos ambientes, embora com ângulos de incidência diferentes de incidências íngremes (ERS-1, ERS-2 e ENVISAT) a rasante (SENTINEL-1A); e, iii) a referência usada na análise da acurácia, baseada nos dados de Geomorfologia em escala original de 1:250.000, levou a algumas inconsistências atribuídas ao detalhamento espacial das feições e ausência de atualização.

Os dados $S A R$ foram apropriados para a detecção de mudanças na linha de costa, no nível regional (escala 1:250.000 ou menor) e atualização anual a decadal, em função da percepção do sensor (resolução espacial e relação sinal/ruído), e em consequência disto, as feições de acresção e erosão foram mapeadas até a unidade mínima de mapeamento de 3,6 ha. A foz do rio Amazonas mostrou significativa dinâmica na porção insular da área de estudo, especificamente entre a costa do Amapá e a ilha de Marajó. Há indícios de equilíbrio entre os processos de erosão e acresção no balanço sedimentar do período entre 1992 a 2015, entretanto há tendência acrescional constatada no período de 2006 a 2015.

\section{Agradecimentos}

Este estudo faz menção ao uso de dados ERS 1/2 e ENVISAT os quais foram fornecidos pela European Space Agency - ESA para o Projeto ID 28494, esta instituição possibilita acesso amplo por meio do Programa ESA's Earth Observation.

\section{Referências Bibliográficas}

ARNESEN, A. S. et al. Monitoring flood extent in the lower Amazon River floodplain using ALOS/PALSAR ScanSAR images. Remote Sensing of Environment, v. 130, p. 51-61, mar. 2013.

ASCHBACHER, J.; MILAGRO-PÉREZ, M. P. The European Earth monitoring (GMES) programme: Status and perspectives. Remote Sensing of Environment, v. 120, n. 2012, p. 3-8, maio 2012.

ASMUS, M. L. et al. Gestão Costeira no Brasil: Instrumentos, fragilidades e potencialidades. Revista de Gestão Costeira Integrada, v. 4, p. 52-57, 2006.

BAATZ, M.; SCHÄPE, A. Multiresolution segmentation: an optimization approach for high quality multiscale image segmentationAngewandte Geographische Informationsverarbeitung XII. Anais...2000

BATISTA, E. . M.; SOUZA-FILHO, P. W. M.; SILVEIRA, O. . F. M. Monitoramento da linha de costa do Parque Nacional do Cabo Orange através da análise multi-temporal de imagens de sensores remotosAnais XIII Simpósio Brasileiro de Sensoriamento Remoto. Anais...Florianópolis: INPE, 2007Disponível em: <http://marte.sid.inpe.br/col/dpi.inpe.br/ sbsr@80/2006/11.15.22.25.58/doc/6621-6628.pdf>

BATISTA, E. DAS M.; SOUZA FILHO, P. W. M. E; SILVEIRA, O. F. M. DA. Avaliação de áreas deposicionais e erosivas em 
cabos lamosos da zona costeira Amazônica através da análise multitemporal de imagens de sensores remotos. Revista Brasileira de Geofísica, v. 27, n. 1, p. 83-96, 2009.

BLASCHKE, T. Object based image analysis for remote sensing. ISPRS Journal of Photogrammetry and Remote Sensing, v. 65 , n. 1, p. 2-16, jan. 2010.

BOAK, E. H.; TURNER, I. L. Shoreline Definition and Detection: A Review. Journal of Coastal Research, v. 214, p. 688-703, jul. 2005.

CONGALTON, R. G.; GREEN, K. Assessing the accuracy of remotely sensed data: principles and practices. New York: CRC Press/Taylor \& Francis, 2009.

COSTA, J. B. S. et al. Neotectônica Da Região Amazônica : Aspectos Tectônicos, Geomorfológicos E Deposicionais. Geonomos, v. 4, n. 2, p. 23-43, 1991.

COUGO, M. et al. Radarsat-2 Backscattering for the Modeling of Biophysical Parameters of Regenerating Mangrove Forests. Remote Sensing, v. 7, n. 12, p. 17097-17112, 2015.

DALRYMPLE, R. W.; ZAITLIN, B. A.; BOYD, R. Estuarine facies models; conceptual basis and stratigraphic implications. Journal of Sedimentary Research, v. 62, n. 6, p. 1130-1146, 1 nov. 1992.

DE ANDRADE, M. M. N. et al. A socioeconomic and natural vulnerability index for oil spills in an Amazonian harbor: a case study using GIS and remote sensing. Journal of environmental management, v. 91, n. 10, p. 1972-80, out. 2010.

DHN, (DIRETORIA DE HIDROGRAFIA E NAVEGAÇÃO). PREVISÕES DE MARÉS. Disponível em: < http://www.mar. mil.br/dhn/chm/box-previsao-mare/tabuas/> . Acesso em: 30 abr. 2016 .

EL-ROBRINI, M. et al. Atlas de erosão e progradação da zona costeira do Estado do Pará - Região Amazônica: Áreas oceânica e estuarina. In: MUEHE, D. (Ed.). . Atlas de Erosão e Progradação da Zona Costeira Brasileira. São Paulo: [s.n.]. p. 1-34.

ESA, (EUROPEAN SPACE AGENCY). The SENTINEL-1 Toolbox (S1TBX). Disponível em: $<$ https://sentinel.esa.int/web/ sentinel/toolboxes/sentinel-1>. Acesso em: 3 jul. 2014.

ESA, (EUROPEAN SPACE AGENCY). ESA Earth Observation Missions. Disponível em: $<$ https://earth.esa.int/ web/guest/missions/esa-operational-eo-missions $>$. Acesso em: 5 maio. 2015a.

ESA, (EUROPEAN SPACE AGENCY). Sentinels Scientific
Data Hub. Disponível em: <https://scihub.copernicus.eu>. Acesso em: 15 fev. 2015 b.

FERRETTI, A. et al. InSAR Principles-Guidelines for SAR Interferometry Processing and Interpretation. Noordwijk: ESA Publications, 2007.

FILHO, P. W. M. S. et al. Environmental sensitivity index (ESI) mapping of oil spill in the amazon coastal zone: The PIATAM Mar project. Revista Brasileira de Geofisica, v. 27, n. SUPPL. 1, p. 7-22, 2009.

FRANÇA, C. F. Morfologia e Mudanças Costeiras da Margem Leste da Ilha de Marajó (PA). Belém: Universidade Federal do Pará, 2003.

FRANÇA, C. F. DE; SOUZA-FILHO, P. W. M. Análise das Mudanças Morfológicas Costeiras de Médio Período na Margem Leste da Ilha de Marajó (PA) em Imagem Landsat. Revista Brasileira de Geociências, v. 33, p. 127-136, 2003.

FRANÇA, C. F. DE; SOUZA FILHO, P. W. M. E; EL-ROBRINI, M. Análise faciológica e estratigráfica da planície costeira de Soure (margem leste da ilha de Marajó-PA), no trecho compreendido entre o canal do Cajuúna e ostuário ParacauariActa Amazonica, 2007.

FURTADO, L. F. DE A.; SILVA, T. S. F.; NOVO, E. M. L. DE M. Dual-season and full-polarimetric $\mathrm{C}$ band SAR assessment for vegetation mapping in the Amazon várzea wetlands. Remote Sensing of Environment, v. 174, p. 212-222, mar. 2016.

GENSAC, E. et al. Seasonal and inter-annual dynamics of suspended sediment at the mouth of the Amazon river: The role of continental and oceanic forcing, and implications for coastal geomorphology and mud bank formation. Continental Shelf Research, v. 118, p. 49-62, abr. 2016.

GEYER, R. W. et al. Physical oceanography of the Amazon shelf. Continental Shelf Research, v. 16, n. 5-6, p. 575-616, jan. 1996.

GHONEIM, E. et al. Nile Delta exhibited a spatial reversal in the rates of shoreline retreat on the Rosetta promontory comparing pre- and post-beach protection. Geomorphology, v. 228, p. 1-14, jan. 2015.

GOBLIRSCH, W.; PASQUALI, P. Algorithms for Calculation of Digital Surface Models from the Unwrapped Interferometric Phase. Proceedings of International Geoscience and Remote Sensing Symposium (IGARSS'96), p. 656-658, 1996.

GUIMARÃES, J. T. F. GEOMORFOLOGIA, MUDANÇAS NA FONTE DE MATÉRIA ORGÂNICA E VEGETAÇÃO EM PLANÍCIES DE MARÉ PRÓXIMAS A FOZ DO RIO 
AMAZONAS DURANTE O HOLOCENO. [s.1.] Universidade Federal do Pará, 2011a.

GUIMARÃES, U. S. ANÁLISE INTEGRADADAPAISAGEM PARA AVALIAÇÃO DA VULNERABILIDADE À PERDA DE SOLO DAS MARGENS DA BAÍA DE MARAJÓ, ESTADO DO PARÁ. [s.l.] Universidade Federal do Pará, 2011b.

HARALICK, R. M.; SHANMUGAM, K.; DINSTEIN, I. Textural Features for Image Classification. IEEE Transactions on Systems, Man, and Cybernetics, v. SMC-3, n. 6, p. 610-621, nov. 1973.

HENDERSON, F. M.; LEWIS, A. J. Principles and applications of imaging radar. Manual of remote sensing, volume 2. [s.l: s.n.]. v. 2

HEROLD, N. D.; HAACK, B. N.; SOLOMON, E. An evaluation of radar texture for land use/cover extraction in varied landscapes. International Journal of Applied Earth Observation and Geoinformation, v. 5, n. 2, p. 113-128, maio 2004.

HUSSAIN, M. et al. Change detection from remotely sensed images: From pixel-based to object-based approaches. ISPRS Journal of Photogrammetry and Remote Sensing, v. 80, p. 91-106, jun. 2013.

IBGE, (INSTITUTO BRASILEIRO DE GEOGRAFIA E ESTATÍSTICA). Censo Demográfico 2010. Disponível em: <http://www.ibge.gov.br/home/estatistica/populacao/ censo2010/>. Acesso em: 20 abr. 2015.

IBGE, (INSTITUTO BRASILEIRO DE GEOGRAFIA E ESTATÍSTICA). Downloads - Geociências. Disponível em: $<$ http://downloads.ibge.gov.br/downloads_geociencias.htm>. Acesso em: 25 abr. 2015.

INMET, (INSTITUTO NACIONAL DE METEOROLOGIA). Banco de Dados Meteorológicos para Ensino e Pesquisa. Disponível em: <http://www.inmet.gov.br/portal/index. php?r=bdmep/bdmep>. Acesso em: 6 abr. 2016.

IPCC. Summary for Policymakers. In: INTERGOVERNMENTAL PANEL ON CLIMATE CHANGE (Ed.). . Climate Change 2013 - The Physical Science Basis. Cambridge: Cambridge University Press, 2014a. p. 1-30.

IPCC, (INTERGOVERNMENTAL PANEL ON CLIMATE CHANGE). Coastal systems and low-lying areas. In: Climate Change 2014: Impacts, Adaptation, and Vulnerability. Part A: Global and Sectoral Aspects. Contribution of Working Group II to the Fifth Assessment Report of the Intergovernmental Panel on Climate Change. United Kingdom and New York:
Cambridge University Press, 2014b. p. 361-409.

JOHNSON, R. A.; WICHERN, D. W. Applied Multivariate Statistical Analysis. [s.1: s.n.]. v. 47

KJERFVE, B. et al. Chapter Twenty Morphodynamics of muddy environments along the Atlantic coasts of North and South America. In: Proceedings in Marine Science. [s.1: s.n.]. v. 4p. 479-532.

KUMAR, T.; PATNAIK, C. Discrimination of mangrove forests and characterization of adjoining land cover classes using temporal C-band Synthetic Aperture Radar data: A case study of Sundarbans. International Journal of Applied Earth Observation and Geoinformation, v. 23, p. 119-131, ago. 2013.

LANG, M. W.; KASISCHKE, E. S. Using C-Band Synthetic Aperture Radar Data to Monitor Forested Wetland Hydrology in Maryland's Coastal Plain, USA. IEEE Transactions on Geoscience and Remote Sensing, v. 46, n. 2, p. 535-546, jan. 2008.

LEE, J.-S.; POTTIER, E. Polarimetric Radar Imaging: From Basics to Applications. [s.1.] CRC Press, 2009.

LU, D. et al. Change detection techniques. International Journal of Remote Sensing, v. 25, n. 12, p. 2365-2401, jun. 2004.

MAGUIRE, D. J.; BATTY, M.; GOODCHILD, M. F. GIS, spatial analysis, and modeling. Redlands: Esri Press, 2005.

MARTORANO, L. G. Estudos climáticos do estado do Pará, classificação climática (Koppen) e deficiência hídrica (Thornthwaite, Mather). [s.l: s.n.].

MASSELINK, G.; HUGHES, M. G.; KNIGHT, J. Introduction to Coastal Processes and Geomorphology. New York: Routledge, 2003.

MATOS, M. DE F. A. DE et al. Estudo sistemático dos processos hidrodinâmicos sazonais de um sistema flúvio-lacustre na região da planície costeira do Amapá , Brasil. Revista Brasileira de Geomorfologia, v. 12, n. 2, p. 59-69, 2011.

MEADE, R. H. et al. Storage and Remobilization of Suspended Sediment in the Lower Amazon River of Brazil. Science, v. 228, n. 4698, p. 488-490, 26 abr. 1985.

MITCHELL, A. L. et al. C- and L-band SAR interoperability: Filling the gaps in continuous forest cover mapping in Tasmania. Remote Sensing of Environment, v. 155, p. 58-68, dez. 2014.

MUEHE, D. Geomorfologia Costeira. In: CUNHA, S. B.; TEIXEIRA, A. J. (Eds.). . Geomorfologia: uma atualização de bases e conceitos. Rio de Janeiro: Bertrand Brasil S. A., 
1994. p. 253-308.

MUEHE, D. Aspectos gerais da erosão costeira no brasil. Mercator, v. 4, n. 7, p. 97-110, 2005.

MUEHE, D. O litoral Brasileiro e sua compartimentação. In: CUNHA, S. B.; GUERRA, A. J. T. (Eds.). . Geomorfologia do Brasil. Rio de Janeiro: Bertrand Brasil S. A., 2006a. p. 273-349.

MUEHE, D. Erosion in the Brazilian coastal zone: an overview. Journal of Coastal Researches (Special Issue), v. 2004, n. 39, p. $43-48,2006 b$.

MUEHE, D. C. E. H. et al. Pulsos Erosivos e Resposta Morfodinâmica Associada a Eventos Extremos na Costa Leste Do Estado do Rio de Janeiro. Revista Brasileira de Geomorfologia, v. 16, n. 3, p. 369-386, 30 set. 2015.

MURA, J. C. Geocodificação Automática De Imagens De Radar De Abertura Sintética Interferométrico : Sistema GeoInSAR. [s.1.] Instituto Nacional de Pesquisas Espaciais, 2001.

NAPIERALSKI, J. et al. Remote Sensing and GIScience in Geomorphological Mapping. In: Treatise on Geomorphology. [s.l: s.n.]. v. 3p. 187-227.

NARVAES, I. DA S.; SANTOS, J. R. DOS; SILVA, A. DE Q. DA. Analysis of structural parameters of forest typologies USING L-band SAR data. Boletim de Ciências Geodésicas, v. 16 , n. 3, p. 475-489, 2010.

NASCIMENTO, W. R. et al. Mapping changes in the largest continuous Amazonian mangrove belt using object-based classification of multisensor satellite imagery. Estuarine, Coastal and Shelf Science, v. 117, p. 83-93, jan. 2013.

NEREM, R. S. et al. Estimating Mean Sea Level Change from the TOPEX and Jason Altimeter Missions. Marine Geodesy, v. 33, n. sup1, p. 435-446, 16 ago. 2010.

NICHOLLS, R. et al. Coastal systems and low-lying areas. Climate Change 2007: Impacts, Adaptation and Vulnerability. Contribution ofWorking Group II to the Fourth Assessment Report of the Intergovernmental Panel on Climate Change, p. 315-356, 2007.

NICHOLlS, R. J.; CAZENAVE, A. Sea-Level Rise and Its Impact on Coastal Zones. Science, v. 328, n. 5985, p. 1517-1520, 18 jun. 2010.

NITTROUER, C. A. et al. The deltaic nature of Amazon shelf sedimentation. Geological Society of America Bulletin, v. 97, n. 4 , p. $444-458,1986$.

NITTROUER, C. A. et al. An introduction to the geological significance of sediment transport and accumulation on the
Amazon continental shelf. Marine Geology, v. 125, n. 3-4, p. 177-192, jul. 1995.

PEREIRA, L. C. C. et al. Seasonal changes in oceanographic processes at an equatorial macrotidal beach in northern Brazil. Continental Shelf Research, v. 43, p. 95-106, jul. 2012.

POLIZEL, S. P.; ROSSETTI, D. D. F. Caracterização Morfol[ogica do Delta do Rio Doce (ES) com Base em Análise Multissensor. Revista Brasileira de Geomorfologia, v. 15, n. 2, p. 311-326, 18 ago. 2014.

PROJETO RADAM BRASIL. Folha SA.22 Belém - Geologia, Geomorfologia, Solos, Vegetação e Uso Potencial da TerraRio de Janeiro, 1974.

QI, Z. et al. A three-component method for timely detection of land cover changes using polarimetric SAR images. ISPRS Journal of Photogrammetry and Remote Sensing, v. 107, p. 3-21, set. 2015.

REIGBER, C. et al. Impact of precise orbits on SAR interferometryERS SAR interferometry, Proceedings of the Fringe 96 Workshop. Anais...Zurich: European Space Agency, 1996

REJAUR RAHMAN, M.; SAHA, S. K. Multi-resolution segmentation for object-based classification and accuracy assessment of land use/land cover classification using remotely sensed data. Journal of the Indian Society of Remote Sensing, v. 36, n. 2, p. 189-201, 2008.

RESCHKE, J. et al. Capability of C-Band SAR for Operational Wetland Monitoring at High Latitudes. Remote Sensing, v. 4, n. 12 , p. 2923-2943, 1 out. 2012.

RICHARDS, J. A.; JIA, X. Remote Sensing Digital Image Analysis: An Introduction. New York: Springer, 2006. v. 46

RODRIGUES, S. W. P.; SOUZA-FILHO, P. W. M. Use of MultiSensor Data to Identify and Map Tropical Coastal Wetlands in the Amazon of Northern Brazil. Wetlands, v. 31, n. 1, p. 11-23, 11 fev. 2011

RODRIGUES, S. W. P.; SOUZA-FILHO, P. W. M. Mapping of environmental sensitivity index to oil spill from Landsat TM images: "A study case on the Amazon coastal plain". Revista Brasileira de Geofisica, v. 30, n. 4, p. 533-543, 2012.

SANTOS, M. S. T.; AMARO, V. E. Dinâmica Sazonal De Processos Costeiros E Estuarinos Em Sistema De Praias Arenosas E Ilhas Barreira No Nordeste Do Brasil. Revista Brasileira de Geomorfologia, v. 2, p. 93-95, 2013.

SANTOS, V. F. Ambientes Costeiros Amazônicos: Avaliação 
de Modificações Ambientais por Sensoriamento Remoto. Niteroi: Universidade Federal Fluminense, 2006.

SANTOS, A. L. S. DOS; AMARO, V. E.; SANTOS, M. S. T. Geodésia de Precisão Aplicada à Análise da Evolução Morfodinâmica de Curto Prazo na Ilha Barreira do Corta Cachorro, Litoral do Rio Grande do Norte, Nordeste do Brasil. Revista Brasileira de Geomorfologia, v. 15, n. 3, p. 18, 23 set. 2014.

SCHREIER, G. SAR Geocoding: Data and Systems. Karlsruhe: Wichmann, 1993.

SILVA, I. R. et al. Modelagens de Clima de Ondas e Transporte Sedimentar Utilizando o SMC-Brasil: Aplicações para a Praia do Forte, Litoral Norte do Estado da Bahia. Revista Brasileira de Geomorfologia, v. 17, n. 4, 15 dez. 2016.

SILVEIRA, J. D. A. Morfologia do litoral. In: Brasil a terra e o homem. São Paulo: Companhia Editora Nacional, 1964. p. 253-305.

SOUZA-FILHO, P. W. M. et al. Zona Costeira Amazônica: O cenário regional e os indicadores bibliométricos em C\&T. In: Bibliografia da Zona Costeira Amazônica. Belém: Museo Paraense Emílio Goeldi / Universidade Federal do Pará / Petrobras, 2005. p. 400.

SOUZA-FILHO, P. W. M. et al. Discrimination of coastal wetland environments in the Amazon region based on multipolarized L-band airborne Synthetic Aperture Radar imagery. Estuarine, Coastal and Shelf Science, v. 95, n. 1, p. 88-98, nov. 2011

SOUZA, L. S. B.; ROSSETTI, D. F. Caracterização da rede de drenagem na porção leste da ilha do Marajó e implicações tectônicas. Revista Brasileira de Geomorfologia, v. 12, n. 1, p. 69-83, 2011 .

SOUZA FILHO, P. W. M.; FARIAS MARTINS, E. D. S.; DA COSTA, F. R. Using mangroves as a geological indicator of coastal changes in the Bragança macrotidal flat, Brazilian Amazon: A remote sensing data approach. Ocean \& Coastal Management, v. 49, n. 7-8, p. 462-475, jan. 2006.
TEIXEIRA, S. G. Radar de abertura sintética aplicado ao mapeamento e reconhecimento de zonas úmidas costeiras. Belém: Universidade Federal do Pará, 2011.

TESSLER, M. G.; GOYA, S. C. Processos Costeiros Condicionantes do Litoral Brasileiro. Revista do Departamento de Geografia, v. 17, n. 8, p. 11-23, 2005.

TORRES, R. et al. GMES Sentinel-1 mission. Remote Sensing of Environment, v. 120, p. 9-24, maio 2012.

TREBOSSEN, H. et al. Monitoring coastal evolution and associated littoral hazards of French Guiana shoreline with radar images. Comptes Rendus Geoscience, v. 337, n. 13, p. 1140-1153, 2005.

TRIMBLE. eCognition ® Developer 8MünchenTrimble Germany GmbH, , 2014.

UNDP, (UNITED NATIONS DEVELOPMENT PROGRAMME). Frontline Observations on Climate Change and Sustainability of Large Marine EcosystemsLarge Marine Ecosystems. New York: [s.n.].

UNITED NATIONS. The First Global Integrated Marine Assessment. New York: [s.n.].

USGS, (UNITED STATES GEOLOGY SURVEY). EarthExplorer - USGS. Disponível em: $<$ http://earthexplorer. usgs.gov/>. Acesso em: 5 abr. 2015.

WANG, Y. Remote sensing of coastal environments. [s.1.] CRC Press/Taylor \& Francis, 2010.

WEGMÜLLER, U. et al. DEM generation using ERS-ENVISAT interferometry. Journal of Applied Geophysics, v. 69, n. 1, p. 51-58, set. 2009.

WOODHOUSE, I. H. Introdution to Microwave Remote Sensing. New York: CRC Press/Taylor \& Francis, 2006.

ZAMBONI, A.; NICOLODI, J. L. Atlas do Macrodiagnóstico da Zona Costeira e Marinha do Brasil. Disponível em: $<\mathrm{http}: / /$ www.mma.gov.br/component/k2/item/7562?Itemid=866>. Acesso em: 16 fev. 2016. 